\title{
Best-of-Three Contest Experiments: Strategic versus Psychological Momentum
}

\author{
Shakun D. Mago ${ }^{a}$, Roman M. Sheremeta ${ }^{b}$ and Andrew Yates ${ }^{c}$ \\ ${ }^{a}$ Department of Economics, Robins School of Business, University of Richmond, \\ 28 Westhampton Way, Richmond, VA 23173, USA \\ ${ }^{\mathrm{b}}$ Argyros School of Business and Economics, Chapman University, \\ One University Drive, Orange, CA 92866, USA \\ ${ }^{\mathrm{c}}$ Department of Economics, University of North Carolina at Chapel Hill, \\ Chapel Hill, NC 27599, USA
}

December 2, 2012

\begin{abstract}
We conduct an experimental analysis of a best-of-three contest. Intermediate prizes lead to higher efforts, while increasing the role of luck (as opposed to effort) leads to lower efforts. Both intermediate prizes and luck reduce the probability of contest ending in two rounds. The patterns of players' efforts and the probability that a contest ends in two rounds are consistent with 'strategic momentum', i.e., momentum generated due to strategic incentives inherent in the contest. We do not find evidence for 'psychological momentum', i.e., momentum which emerges when winning affects players' confidence. Similar to previous studies of contests, we find significantly higher efforts than predicted and strong heterogeneity in effort between subjects.
\end{abstract}

JEL Classifications: C72, C91, D72

Keywords: best-of-three contest, experiments, strategic momentum, psychological momentum

Corresponding author: Shakun D. Mago; E-mail: sdatta@ richmond.edu; Telephone: 804-287-6631; Fax: 804-2898878

* The earlier version of this paper circulated under the title "Best-of-Three Contests: Experimental Evidence." We thank Tim Cason, Dan Kovenock, seminar participants at Virginia Commonwealth University, participants at the International Economic Science Association conference in Copenhagen, Tournaments Contests and Relative Performance Evaluation conference in Raleigh, and Economic Science Association conference in Tucson for helpful comments. We also gratefully acknowledge comments from the associate editor and two anonymous referees. University of Richmond provided funds for conducting the experiments. Any remaining errors are ours. 


\section{Introduction}

Many contests feature a best-of-N structure in which players compete over a sequence of rounds and the first player to win a majority of the rounds wins the contest. The sequential nature of the contest leads to several interesting predictions about the pattern of effort exerted by players during the various rounds. These effort choices, in turn, imply predictions about the pattern of outcomes. Examples of such contests include patent races (Fudenberg et al., 1983), presidential nomination campaigns (Klumpp and Polborn, 2006) and sport competitions (Szymanski, 2003). Patent races, for instance, are characterized by a dynamic multi stage setting where the first firm to win the race is awarded patent protection. They have dynamic uncertainty because the "incentive to invest in $\mathrm{R} \& \mathrm{D}$ may change as the race unfolds, according to the position of a firm in the race relative to its competitors and relative to the end of the race" (Zizzo, 2002, pg. 878); as well as technological uncertainty because the firm making the most investment may not always win the patent. We examine a best-of-N contest that encapsulates both dynamic and technological uncertainty and analyze how inclusion of intermediate prizes and varying level of uncertainty affects behavior. Our design also enables us to separate the behavioral explanations of various choices from the strategic incentives inherent in the contest.

Empirical evidence on patent races is inconclusive (Zizzo, 2002), and much of the extant empirical literature focuses on sports contests (Szymanski, 2003). Because it is difficult to measure the actual effort expended by players in sports contests, almost all these studies focus solely on whether the pattern of outcomes is consistent with theoretical predictions (baseball: Mosteller 1952; tennis: Jackson 1993, Malueg and Yates 2010; golf: McFall et al. 2009; baseball, basketball, and hockey: Ferrall and Smith, 1999). However, this methodology provides only an indirect measure of effort. Laboratory data is untainted by various confounding factors 
(such as players' abilities and skill) that afflict the field data, and therefore allows a direct test of contest incentives. In this paper, we use laboratory experiments to obtain empirical evidence on the pattern of effort and outcomes in the simplest possible best-of-N contest, a best-of-three contest.

In a best-of-three contest between two ex-ante symmetric players, the first player to win two rounds is the contest winner. We assume that in each round the winner is determined probabilistically, and the probability of winning a round is a function of the players' effort as well as luck. Economic theory predicts that players will exert equal effort in the first round and in the third round (if one occurs). In the second round, the relative efforts are determined by the parameters of the contest. In our baseline treatment, the winner of the first round has a higher effective value associated with winning the second round, and hence will exert more effort. Translating effort into outcomes implies that both players are equally likely to win the first round. The winner of the first round is more likely to win the second round; but if the contest goes to the third round, then both players are once again are equally likely to win. Thus, the outcome of the first round has an asymmetric effect on the second round efforts by ex-ante symmetric players, and equilibrium play explains the emergence of a 'hot hand' (winning streak that occurs more often than predicted by chance). We say that the winner of the first round exhibits 'strategic momentum' in the second round to reinforce the idea that this increase in the probability of winning is a consequence of the contest incentive structure.

In addition to strategic momentum, players in a best-of-three contest may also exhibit 'psychological momentum.' Folk psychology suggests numerous (and often contradictory) ways in which relative position in the contest can affect performance. While there is no single definition of psychological momentum, it is often based on the maxim 'success breeds success,' 
i.e., winning a round affects players' confidence and makes them more likely to win the next round (Vallerand et al., 1988; Baker et al., 1994a, 1994b; Kerick et al., 2000; Dorsey-Palmeteer and Smith, 2004).

Our experimental design exploits situations in which strategic and psychological momentum give rise to different effort choices and outcomes. Our first piece of evidence to distinguish between the two momentums lies in the structure of the best-of-three contest itself. As mentioned earlier, in our baseline treatment the effort choices in the second round exhibit strategic momentum, but in the third round players are symmetric and so there is no strategic momentum: the optimal strategy for both players is to exert equal effort. However, if we observe that the winner of the second round is more likely to win the third round, then this is evidence in support of psychological momentum. To obtain additional validation, we employ a treatment with parameters such that there is no strategic momentum in any round. In this case, if we observe that the winner of the first round is more likely to win the second round, then again this is evidence in support of psychological momentum.

Our experimental design also encompasses comparative statics for two treatment variables. The first variable is an intermediate prize for winning an individual round. Theory predicts that intermediate prizes leads to an increase in effort, and a decrease in the probability of contest ending in two rounds. The second treatment variable is the degree to which luck rather than effort determines the winner of a round. Theory predicts that an increase in the role of luck leads to a decrease in effort and a decrease in the probability of contest ending in two rounds.

Existing experimental studies of contests investigate a diverse array of issues, such as entry costs, player asymmetry, effect of carryover, risk aversion, multiple prizes, etc (e.g., Millner and Pratt, 1989, 1991; Potters et al., 1998; Davis and Reilly, 1998; Anderson and 
Stafford, 2003; Schmitt et al., 2004; Fonseca, 2009; Anderson and Freeborn, 2010; Sheremeta and Zhang, 2010; Price and Sheremeta, 2011; Cason et al., 2012; Kimbrough and Sheremeta, 2012; Savikhin and Sheremeta, 2012). For a comprehensive review of the experimental literature on contests see Dechenaux et al. (2012). However, most experimental studies consider only single round contests. Studies on multiple round contests are few and relatively recent, and often consider an elimination contest rather than best-of-N structure. Parco et al. (2005) and Amaldoss and Rapoport (2009) consider an elimination setting wherein the players compete within their own groups by expending efforts, and the winner of each group proceeds to the second round. In the second round, players compete with one another to win a prize by expending additional efforts subject to a budget constraint. Sheremeta (2010a, 2010b) examines behavior in multiround elimination contests without budget constraints. Deck and Sheremeta (2012) examine a multi-round contest in which players have asymmetric objectives. To the best of our knowledge, there are only three experimental studies on best-of-N contests. Zizzo (2002) examines the aggressiveness of players in a multi-round contest that simulates a patent race (the first player to win 10 rounds wins the contest). Unlike our design, however, subjects in Zizzo (2002) are budget constrained. This confounds the role of momentum with the task of determining the optimal allocation of resources across different rounds. Irfanoglu et al. (2013) focus mainly on the difference between behavior in sequential and simultaneous best-of-three contests. Finally, Mago and Sheremeta (2012) examine behavior in a multi-battle contest with deterministic all-pay contest success function, that is, player who exerts higher effort wins the battle with certainty.

The primary focus of our paper is to examine the patterns of effort and outcomes in a contest with the best-of-three structure to distinguish between strategic and psychological momentum. Our results are consistent with strategic momentum, and we do not find any 
evidence for psychological momentum. Our results, therefore, supplement a recent field study by Malueg and Yates (2010), who also document evidence of strategic momentum but not psychological momentum in tennis matches between equally skilled players. Malueg and Yates only observe outcomes and must infer efforts. Our results verify that effort choices do indeed lead to strategic momentum. Taken together with Malueg and Yates' (2010) results, our findings offer strong evidence that players recognize and respond to the varying incentives during the course of a best-of-three contest.

We extend the theoretical literature on best-of-three contests by analyzing the impact of intermediate prizes. We also contribute to the experimental literature by testing the Nash equilibrium prediction and comparative statics with respect to both intermediate prizes and luck. Almost without exception, existing experimental studies on contests provide evidence of effort expenditure that is in excess of Nash equilibrium levels (for a review on the overbidding phenomena see Sheremeta, 2013), but confirm the various models' comparative statics predictions. Our results are similarly consistent. We find strong support for our comparative statics predictions, but we also find significantly higher efforts than predicted and strong heterogeneity in effort between subjects. We discuss a number of possible explanations for these findings.

\section{Theoretical Model}

Several papers analyze the theory of effort expenditure in a best-of-three contest. These papers are differentiated by the way in which they model the competition that occurs in each round. Konrad and Kovenock (2009) use an all-pay auction, Ferrall and Smith (1999) use a rankorder tournament, and Klumpp and Polborn (2006) use a Tullock contest. 
We extend Klumpp and Polborn's analysis to allow for intermediate prizes. Two riskneutral and equally-skilled players $i$ and $j$ face each other in as many as three successive rounds. The first player to win two rounds is the contest winner. In each round, players select efforts $x_{i}$ and $x_{j}$. The contest success function $p\left(x_{i}, x_{j}\right)$ specifies the probability that player $i$ wins the round as a function of players' efforts. Following Tullock (1980), we have

$$
p\left(x_{i}, x_{j}\right)=x_{i}^{r} /\left(x_{i}^{r}+x_{j}^{r}\right) \text {. }
$$

The exponent $r$ reflects how sensitive the probability of winning is to the players' relative expenditure and can be interpreted as the degree of 'luck' in the contest. As $r$ decreases, luck plays a more important role. As $r$ approaches zero, the probability of winning is equivalent to a random coin toss, regardless of the individual effort choices. ${ }^{1}$ Both players value winning the contest at $v$, and there is an additional intermediate prize $d$ for winning individual rounds.

To characterize the players' effort choices, we apply backward induction. Let $V_{i}(m, n)$ be the expected payoff to player $i$ when player $i$ needs to win $m$ more rounds to win the contest and player $j$ needs to win $n$ more rounds. We start at the third and final round. The winner of the third round receives the final prize $v$ for winning the overall contest, and an intermediate prize $d$ for winning the third round. The loser of the third round receives 0 . Therefore the expected payoff for player $i$ is

$$
V_{i}(1,1)=p\left(v+d-x_{i}\right)+(1-p)\left(-x_{i}\right)=p(v+d)-x_{i}
$$

and the expected payoff for player $j$ is

$$
V_{j}(1,1)=(1-p)\left(v+d-x_{j}\right)+p\left(-x_{j}\right)=(1-p)(v+d)-x_{j} .
$$

This is equivalent to a standard single-round Tullock contest in which player $i$ 's value of winning is $V=v+d$ and player $j$ 's value of winning is $W=v+d$. The Nash equilibrium efforts are well known and are given by

\footnotetext{
${ }^{1}$ We assume that $0<r \leq 1$ which ensures that a unique pure strategy Nash equilibrium exists.
} 


$$
x_{i}{ }^{*}=r \rho^{r} V /\left(1+\rho^{r}\right)^{2} \text { and } x_{j}^{*}=r \rho^{r} W /\left(1+\rho^{r}\right)^{2},
$$

where $\rho=W / V$ is the ratio of players' values. Note that the ratio of players' efforts is equal to the ratio of their values (Malueg and Yates, 2005). It therefore follows that in the third round of our best-of-three contest, players exert equal effort because they have the same value for winning the round. From (4), the third round Nash equilibrium efforts are

$$
x_{i}^{*}=x_{j}^{*}=r(v+d) / 4 \text {. }
$$

In terms of comparative statics, equilibrium effort increases as value of winning (including intermediate prize $d$ ) increases, and as luck plays less of a role ( $r$ increases). The expected payoffs for the players can be found by substituting (5) into (2) and (3).

Stepping backwards to analyze the second round, we can, without loss of generality, assume that player $i$ has won the first round. If player $i$ wins the second round the contest concludes; player $i$ receives the final prize $v$ for winning the overall contest and an intermediate prize $d$ for winning the second round while player $j$ receives zero. If, however, player $j$ wins the second round the contest moves to the third round, and player $i$ receives the third round expected payoff $V_{i}(1,1)$ while player $j$ receives an intermediate prize $d$ and the third round expected payoff $V_{j}(1,1)$. Therefore, the expected payoff for player $i$ in the second round is

$$
V_{i}(1,2)=p\left(v+d-x_{i}\right)+(1-p)\left(V_{i}(1,1)-x_{i}\right)=V_{i}(1,1)+p\left(v+d-V_{i}(1,1)\right)-x_{i}
$$

and the expected payoff for player $j$ in the second round is

$$
V_{i}(1,2)=(1-p)\left(d+V_{j}(1,1)-x_{j}\right)+p\left(-x_{j}\right)=(1-p)\left(V_{j}(1,1)+d\right)-x_{j}
$$

This is equivalent to a standard single-round Tullock contest in which player $i$ 's 'effective' value of winning is $V=v+d-V_{i}(1,1)$ and player $j$ 's 'effective' value of winning is $W=d+V_{j}(1,1){ }^{2}$ The Nash equilibrium efforts in the second round can be found by substituting these values into

\footnotetext{
${ }^{2}$ Note that the value $V_{i}(1,1)$ is the expected payoff in round 3 and does not depend on the effort $x_{i}$ in the current round.
} 
(4). This yields a complicated expression for individual player efforts, but essential insight into the second round behavior can be gleaned by examining the ratio of players' efforts. We have

$$
x_{j}{ }^{*} / x_{i}^{*}=W / V=((v+d)(1 / 2-r / 4)+d) /((v+d)(1 / 2+r / 4)) \text {. }
$$

This ratio may be greater than, equal to, or less than one, depending on the values of the parameters. In particular, player $i$ will exert more effort than player $j$ if $d<r v /(2-r)$, player $i$ will exert less effort than player $j$ if $d>r v /(2-r)$, and the players will exert equal effort if $d=r v /(2-r)$. It bears highlighting that in cases where player $i$ exerts more effort than player $j$, we have strategic momentum. This momentum emerges endogenously in round 2 , because although winning the overall contest has same value to both players, players may have different effective values for winning the round.

Finally, consider the first round. If player $i$ wins the first round, she receives the intermediate prize $d$ and the expected payoff $V_{i}(1,2)$. If player $i$ loses the first round, she receives the expected payoff $V_{i}(2,1)$. Therefore, the expected payoff for player $i$ in the first round is

$$
V_{i}(2,2)=p\left(d+V_{i}(1,2)-x_{i}\right)+(1-p)\left(V_{i}(2,1)-x_{i}\right)=V_{i}(2,1)+p\left(d+V_{i}(1,2)-V_{i}(2,1)\right)-x_{i}
$$

and the expected payoff for player $j$ in the first round is

$$
V_{j}(2,2)=(1-p)\left(d+V_{j}(2,1)-x_{j}\right)+p\left(V_{j}(1,2)-x_{j}\right)=V_{j}(1,2)+(1-p)\left(d+V_{j}(2,1)-V_{j}(1,2)\right)-x_{i}
$$

This is equivalent to a standard single round Tullock contest in which $V=\left(d+V_{i}(1,2)-V_{i}(2,1)\right)$ and $W=\left(d+V_{j}(2,1)-V_{j}(1,2)\right)$. By symmetry, if player $i$ has lost rather than won the first round,

$$
V_{i}(2,1)=V_{j}(1,2) \text { and } V_{j}(2,1)=V_{i}(1,2)
$$

so that $V=W$. Once again players have equal effective values for winning the round and so they exert equal effort in the first round. Comparative statics regarding $d$ and $r$ remain the same as in round 3. Note, however, that the effective value of winning the first round is lower than the 
effective value of winning the third round. Therefore, if the contest goes to the third round, both players exert greater effort than in earlier rounds.

Player's effort choices have an immediate consequence on the probability of the contest ending in 2 or 3 rounds. If both players exert equal effort in every round, then the best-of-three contest is equally likely to end in two as in three rounds. However, if in round 2 the first round winner exerts greater effort than the first round loser, then the contest is more likely to end in 2 rounds. Furthermore, this likelihood is positively related to the difference between effort choices of round 1 winner and round 1 loser. Since both players' absolute effort increases in prize value, it follows that the relative difference between their effort choices, and consequently the likelihood of early termination, will be lower with the institution of intermediate prizes.

Our theoretical model illustrates how strategic momentum results from equilibrium play. However, laboratory experiments feature human subjects who may also experience psychological momentum. Psychological literature suggests that psychological momentum can be bi-directional (e.g., Vallerand et al., 1988; Kerick et al., 2000). This means that the 'encouraged' winner of a given round may experience positive psychological momentum and the 'discouraged' loser may experience negative psychological momentum. A simple way to incorporate this idea into a best-of-three contest is to assume that psychological momentum leads the winner of a given round to exert more effort in the next round than the loser of a given round. Thus, psychological momentum may occur in both second and third round, regardless of the underlying parameter values. 


\section{Experimental Environment}

\subsection{Experimental Design and Hypotheses}

Table 1 summarizes our experimental design and parameters. We employ three features: "H" denotes a high value for $r$, "L" denotes a low value for $r$, and "I" denotes an intermediate prize. In our baseline HI treatment, the value for $r$ is high $(r=1)$ and there is an intermediate prize for winning an individual round ( $d=25$ experimental francs). We include two control treatments. First, to analyze the impact of intermediate prize we include the $\mathrm{H}$ treatment. In the $\mathrm{H}$ treatment, there is no intermediate prize $(d=0)$, otherwise it is identical to the HI treatment. Second, to analyze the impact of luck we consider an alternative value for $r$. In the LI treatment, the value for $r$ is low $(r=0.4)$, otherwise it is identical to the HI treatment. Our choice of parameters also enables us to distinguish between strategic and psychological momentum. HI and $\mathrm{H}$ treatments feature strategic momentum in the second round because $d<r v /(2-r)$, so the theory predicts that the winner of the first round will exert more effort in the second round than the loser of the first round. In the LI treatment, $d$ and $r$ were chosen such that $d=r v /(2-r)$, so the theory predicts that both players exert equal effort in the second round and there is no strategic momentum. There is no strategic momentum in round 3 for all treatments.

Table 1 presents the equilibrium efforts in each round, the expected payoffs, and the probability of contest ending in two rounds for all three treatments. In all three treatments the value of the final prize is $v=100$ experimental francs. The theoretical predictions in Table 1 suggest a number of hypotheses. The first three concern comparative statics: ${ }^{3}$

\footnotetext{
${ }^{3}$ These comparative statics are based on our experimental parameters. They match the differential comparative statics predicted by the theory, with one exception: the effect of a marginal increase in luck on the round 2 effort by the round 1 loser is ambiguous in theory.
} 
Hypothesis 1: Comparing HI versus H treatment, (a) intermediate prizes lead to higher effort in all rounds by both players; (b) intermediate prizes reduce the probability of contest ending in two rounds.

Hypothesis 2: Comparing HI versus LI treatment, (a) lower $r$ (higher role for luck) leads to lower effort in all rounds by both players; (b) lower $r$ (higher role for luck) reduces the probability of the contest ending in two rounds.

Hypothesis 3: In all treatments, effort in round 3 is higher than effort in rounds 1 and 2.

The next two hypotheses concern the features of strategic momentum:

Hypothesis 4: $\mathrm{In} \mathrm{HI}$ and $\mathrm{H}$ treatments, (a) round 1 winner exerts more effort in round 2 than round 1 loser. In LI treatment, (b) both winner and loser of round 1 exert the same effort in round 2 .

Hypothesis 5: In all treatments, round 2 winner exerts the same effort in round 3 as round 2 loser.

Note that evidence in favor of Hypothesis $4 \mathrm{~b}$ and Hypothesis 5 provides evidence against psychological momentum.

\subsection{Experimental Procedures}

A total of 108 subjects participated in nine sessions with 12 subjects per session. All subjects were undergraduate students at Chapman University. Subjects participated in only one session of this study, although some subjects had previously participated in other unrelated economics experiments.

The experiment was programmed and conducted with the software z-Tree (Fischbacher, 2007). No communication between subjects was permitted and all choices and information were 
transmitted via computer terminals. At the beginning of each session, subjects received an initial endowment of $\$ 15$ to cover potential losses. Each experimental session proceeded in two parts: a risk assessment part and a best-of-three contest part. Subjects were given instructions, available in the Online Appendix, at the beginning of each part. The experimenter read the instructions aloud, so the information contained therein is assumed to be common knowledge. Subjects then completed an online quiz to verify their understanding of the instructions. The experiment started only after all subjects had completed the quiz, and explanations were provided for any incorrect answers. In the risk assessment part of the experiment, subjects made 15 choices in simple lotteries, similar to Holt and Laury (2002). This method was used to elicit subjects' risk preferences.

In the contest part of the experiment, subjects participated in 20 periods of play in one of the three treatments. In each period, subjects played a best-of-three contest with a randomly and anonymously selected opponent. The experimental implementation of the contest mimicked the theory described above, with effort variable $x_{i}$ referred to as the player's 'bid. ${ }^{44}$ Subjects were told the structure of the best-of-three contest and were given detailed instructions on how their bid and their opponent's bid were combined in the relevant contest success function to determine the probability of winning a given round. Subjects were also informed that by increasing their bids, they would increase their chance of winning the round and that, regardless of who wins the round, all subjects would have to pay their bids (money spent on bidding was subtracted from the

\footnotetext{
${ }^{4}$ In our experiment "effort" is an abstract concept, and is represented by a "bid." This notion is consistent with previous contest literature where effort is used to describe any allocation decision such as research and development investment choice (Zizzo, 2002), campaign expenditures (Klumpp and Polborn, 2006), bidding behavior (Sheremeta, 2011). An alternative design choice would be to use "real effort" such as solving mazes (Freeman and Gelber, 2010), optimization problems (van Dijk et al., 2001), or adding numbers (Cason et al., 2010). However, real effort tasks involve fatigue, boredom, excitement and other affectations which are not modeled by the theory (van Dijk et al., 2001). Our primary motivation is to disentangle the behavioral explanations of various effort choices from the strategic incentives inherent in the contest. Since psychological momentum measures intrinsic motivations at play, inclusion of other uncontrolled-for social dimensions would dilute the result and weaken the exposition. By focusing on abstract choices, we are able to avoid any framing issues.
} 
initial endowment of $\$ 15$ that was given to the subjects to cover potential losses). In each round of the contest, subjects made their bids (any number of francs between 0 and 100, including 0.1 decimal points). ${ }^{5}$ After subjects submitted their bids, the computer chose the winner of that round by implementing a lottery with probabilities defined by the contest success function and the players' bids. At the end of each round, computer displayed own bid, opponent's bid, and the result of the lottery draw. A period lasted either two or three rounds. The period ended when one of the players won two rounds ("best of three"). At the end of each period subjects were randomly re-matched with a new opponent.

We took several steps to help subjects understand the role of the contest success function in determining the contest outcome. We provided subjects with a probability table which showed the chance of winning a round based on their own bid and the other subject's bid. In the table a subject could find, for example, that if his bid is 50 francs while the other participant's bid is 30 francs then his chance of winning the round is 0.63 in the LI treatment $(0.55$ in the $\mathrm{H}$ and $\mathrm{HI}$ treatments). To assist subjects with more precise probability calculations, we also provided them with Excel calculators. Subjects could use these calculators at any point of time to find their chance of winning a round for any combination of bids.

At the end of the experiment, 2 out of 20 periods in the contest part of the experiment were randomly selected for payment. ${ }^{6}$ The sum of the earnings for these 2 periods was

\footnotetext{
${ }^{5}$ Our decision not to constrain individual bidding (i.e., 100 francs is substantially higher than the highest possible equilibrium bid of 31.3 , see Table 1) was driven by the fact that artificial budget constraint may confound the role of momentum with the task of determining the optimal allocation of constrained resources across different rounds. Assuming non-limiting budget provides a clean framework to analyze strategic versus psychological momentum. Moreover, the majority of theoretical models (including the one used in the current study) assume no budget constraints, arguing that such constraints are unlikely to be binding in the world of competitive capital markets where it is relatively easy to borrow money (D'Avolio, 2002). Finally, enforcing even non-binding budget constraints on subjects may unexpectedly affect subjects' behavior (Sheremeta, 2011). Therefore, to be consistent with the theoretical model and to avoid potential unintended behavioral consequences, we decided not to restrict subjects' strategy space.

${ }^{6} 2$ periods were selected at random to control for intra-experimental income effects (McKee, 1989).
} 
exchanged at rate of 25 experimental francs = US \$1. Subjects were also paid for 1 out of the 15 decisions made in the risk assessment part of the experiment. On average, subjects earned \$20 each, which was paid anonymously and in cash. The experimental sessions lasted about 90 minutes.

\section{Results}

\subsection{Comparative Statics Results}

Table 2 summarizes the average effort in each round, total effort and payoffs, and the likelihood of contest ending in two rounds. Figure 1 displays the time series of average total effort over all 20 periods. Consistent with other experimental studies of contests we find persistent and significant over-dissipation in all three treatments. In Section 4.3, we explore possible reasons for this over-dissipation. It is important to note that although subjects expend significantly more effort than predicted, aggregate effort patterns remain sensitive to the Nash prediction. Comparing across treatments, total effort in all three treatments is in qualitative agreement with the equilibrium predictions (average total effort is 76.3 in HI, 60.8 in $\mathrm{H}$ and 58.2 in LI).

Table 3 reports the estimation results of different panel models where individual subjects represent the random effects, and the standard errors are clustered at the session level. The dependent variable in specifications (1) and (2) is the subject's total effort in the three rounds and the independent variables are a period trend and a treatment HI dummy-variable. The estimation results indicate that total effort expended in the HI treatment is significantly higher than the 
effort expended in the $\mathrm{H}$ treatment ( $\mathrm{p}$-value $<0.01)$ and the LI treatment $(\mathrm{p}$-value $<0.01){ }^{7}$ This finding lends strong empirical support for Hypothesis 1a and 2a. The fact that effort in the HI treatment is significantly greater than effort in the LI treatment, suggests that subjects understand that luck plays less of a role in the HI treatment and they increase their efforts accordingly. Similarly, intermediate prizes for individual round wins also elicit higher effort. Nevertheless, while the theory accurately predicts the directional impact of luck and intermediate prizes, the quantitative impact is not as pronounced. Comparing $\mathrm{HI}$ and $\mathrm{H}$ treatment, total effort is predicted to be $37 \%$ lower in the $\mathrm{H}$ treatment but is actually only $20 \%$ lower. The comparison for $\mathrm{HI}$ and LI treatment yields even bigger differences. Effort in the LI treatment is predicted to be $58 \%$ lower than the HI treatment, but the decrease in effort is less than half of that (24\%).

Result 1: Intermediate prizes lead to significantly higher effort by both players (HI versus $\mathrm{H}$ ) while lower $r$ (higher role of luck) leads to significantly lower effort (HI versus LI).

Theory also predicts that intermediate prizes and exponent $r$ influence the probability of contest ending in two rounds. In qualitative agreement with the equilibrium predictions, data indicates that the probability of contest ending in round 2 decreases with intermediate prizes (0.61 in $\mathrm{H}$ versus 0.58 in $\mathrm{HI})$ and with lower $r(0.58$ in $\mathrm{HI}$ versus 0.51 in $\mathrm{LI})$. Table 3 (specifications 3 and 4) reports the estimation of random-effect probit models, where the dependent variable is the indicator of contest ending in 2 rounds and the independent variables are a period trend and a treatment $H I$ dummy-variable. The estimation results indicate that the probability of contest ending in 2 rounds is significantly different when comparing HI and LI treatment $(\mathrm{p}$-value $=0.02)$, but not when comparing $\mathrm{H}$ and $\mathrm{HI}$ treatment $(\mathrm{p}$-value $=0.23)$. The latter result is because the observed probability of contest ending in 2 rounds is significantly

\footnotetext{
${ }^{7}$ These results hold even when we focus only on the last 10 periods when subjects have gained sufficient experience. Total effort in HI treatment is significantly greater than effort in $\mathrm{H}$ treatment (p-value $<0.01)$ and in LI treatment $(\mathrm{p}$-value $=0.03)$. The detailed estimation results are available from the authors upon request.
} 
lower than predicted in the $\mathrm{H}$ treatment. ${ }^{8}$ This finding lends partial empirical support to Hypothesis $1 b$ and $2 b$.

Result 2: The probability of contest ending in two rounds is significantly lower with lower $r$ (HI versus LI), but is not significantly lower with intermediate prizes (HI versus $\mathrm{H}$ ).

Finally, we compare effort in round 3 with effort levels in rounds 1 and 2. Theoretical analysis suggests that in all treatments players should exert the highest effort in round 3 . Table 4 reports the estimation results of random-effect models, where the dependent variable is either effort3-effort1 (specifications 1, 2 and 3) or effort3-effort2 (specifications 4, 5 and 6). We control for time trend by including period as an independent variable and we cluster standard errors at the session level. All specifications indicate that effort in round 3 is significantly higher than effort in rounds 1 and 2 (p-value on the constant term is less than 0.01 in all specifications), and thus provide support for Hypothesis 3.

Result 3: Effort in round 3 is significantly higher than effort in rounds 1 and 2.

\subsection{Strategic versus Psychological Momentum}

Table 2 and Figures 2, 3 and 4 display the average effort choices by players in each of the three rounds. Theory predicts that in the HI and $\mathrm{H}$ treatments, winner of round 1 should have strategic momentum in round 2 (Hypothesis 4). We find support for this in the data. Effort in round 2 by the winner of round 1 exceeds that of the loser (HI: 28.5 versus 23.5 and $\mathrm{H}: 37.0$ versus 28.1). Table 5 reports the estimation results of random-effect models, where the dependent variable is effort2 (specifications 1,2 and 3) and the independent variables are a

\footnotetext{
${ }^{8}$ The observed probability of the contest ending in 2 rounds in HI and LI treatment is not significantly different from prediction (observed versus predicted $-\mathrm{HI}$ : 0.58 versus 0.63 , $\mathrm{p}$-value $=0.51$; LI: 0.51 versus 0.5 . $\mathrm{p}$-value $=$ $0.59)$; but is significantly lower than predicted in the $\mathrm{H}$ treatment $(0.61$ versus 0.75 , p-value $<0.01)$. The detailed estimation results are available from the authors upon request.
} 
period trend and a winl dummy-variable. Specifications (1) and (2) indicate that, in treatments $\mathrm{H}$ and HI, the winner of round 1 (winl) exerts significantly higher effort in round 2 than the loser. Accordingly, the likelihood that round 1 winner wins the overall contest remains greater than 50 percent in both treatments (HI: 58 percent and H: 61 percent). Of course, it is possible that part or all of this momentum in round 2 of the $\mathrm{HI}$ and $\mathrm{H}$ treatments is due to psychological momentum. The second round of the LI treatment offers a more discriminating test. Here, theory predicts no strategic momentum in round 2, i.e., the outcome of round 1 does not influence either player's effort choices in round 2. However, if psychological momentum is present then the round 1 winner should expend higher effort than the loser. Our data indicates that effort chosen by round 1 winner in round 2 is not different from that chosen by round 1 loser (LI: 24.4 versus 23.3; p-value on winl is 0.20 in Specification (3) in Table 5). This implies that the round 1 winner is no more likely to win round 2 . Our finding that the probability of contest ending in round 2 remains close to prediction (51 percent versus 50 percent) is consistent with this result, suggesting no psychological momentum in round 2 of the LI treatment. ${ }^{9}$

Result 4: In $\mathrm{HI}$ and $\mathrm{H}$ treatments, effort in round 2 by round 1 winner is significantly higher than effort by round 1 loser, so the contest is more likely to end in two rounds. (Evidence supporting strategic momentum). In LI treatment, effort in round 2 by round 1 winner is not significantly different from the effort by round 1 loser, so the contest is equally likely to end in two rounds as in three. (Evidence against physiological momentum).

Turning to round 3, theory predicts there should not be any strategic momentum. Both players should exert the same effort in round 3 (Hypothesis 5). However, there may be

\footnotetext{
${ }^{9}$ These results are further substantiated by probit models that include subject random effects, session fixed effects and a time trend. We find that in $\mathrm{HI}$ and $\mathrm{H}$ treatments, the likelihood of winning round 2 is higher for round 1 winner (p-value < 0.01); but in case of LI treatment, round 1 winner is no more likely to win round 2 than round 1 loser $(\mathrm{p}$-value $=0.45)$. The detailed estimation results are available from the authors upon request.
} 
psychological momentum, as success or failure in the second round may affect players in the third round. Using panel data analysis with subject specific random effects and robust standard errors, we find no difference in the round 3 effort chosen by the winner of round 2 compared to the loser of round 2 (H: 33.2 versus 31.7; HI: 40.6 versus 38.1; LI: 25.3 versus 24.3). Specifications (4)-(6) in Table 5 indicate that in treatments H, HI and LI, the effort in round 3 by the winner of round 2 (win2) is not significantly different from the effort by the loser of round 2 .

Result 5: In all treatments, effort in round 3 by round 2 winner is not significantly different than effort by round 2 loser. (Evidence against psychological momentum).

Taken together, Results 4 and 5, allow us to convincingly state that the momentum in the second round of the $\mathrm{HI}$ and $\mathrm{H}$ treatments, which results in a greater likelihood of the contest ending in two rounds, is a result of strategic considerations and not psychological impetus.

As a final note, in our experimental setting it is also possible for psychological momentum to exist across periods. This would imply that a player who won the contest in period $t$ is more likely to exert higher effort in round 1 of period $t+1$. We tried to control for this spillover by randomly selecting only 2 out 20 periods for payment. Moreover, based on the estimation of a random-effect model with standard errors clustered at session level and subjectlevel random effects, we do not find any significant relation between winning in period $t$ and effort in round 1 of period $t+1(\mathrm{p}$-value $=0.34)$, suggesting no psychological momentum across periods. $^{10}$

\subsection{Over-dissipation}

At the beginning of Section 4.1, we noted a striking feature of the data: in all three treatments, subjects over-expend effort relative to the risk-neutral Nash predictions. As is evident

\footnotetext{
${ }^{10}$ The detailed estimation results are available from the authors upon request.
} 
from Table 2 and Figure 1, the magnitude of this difference is large and persistent over time. In the $\mathrm{H}$ and LI treatments, average total effort is around twice the equilibrium prediction $(\mathrm{H}: 60.8$ versus 32; LI: 58.2 versus 21.3), and in the $\mathrm{HI}$ treatment average total effort is about 50 percent larger (76.3 versus 50.5). ${ }^{11}$ Such over-dissipation is not uncommon in experimental literature on contests. For a review of this phenomena and various explanations suggested in the literature see Sheremeta (2013). One such explanation is inexperience. For example, Davis and Reilly (1998) show that overbidding decreases but does not disappear with time. Regressions reported in Tables 3 and 5 show that the inverse of a period trend is positive and significant, which suggests that individual learning is taking place, and that with repetition subjects expend lower efforts. ${ }^{12}$ This is also evident in Figures 1-4. Nevertheless, the difference between predicted and observed effort level remains significant even in the last 5 periods (p-value $<0.01$ ). As a result of this over-dissipation, the observed payoffs in all three treatments are significantly lower than expected (p-value $<0.01)$.

Result 6: There is significant aggregate over-dissipation in all treatments. The level of over-dissipation decreases over time, but remains positive and significant.

Furthermore, it is important to note that while over-dissipation does not distort the qualitative comparative statics results (Results 1 and 2), it does influence the quantitative analysis. For example, when testing Hypotheses 1 and 2, we observed that the effort does not fall

\footnotetext{
${ }^{11}$ To find empirical support for these conclusions we estimated a simple panel regression separately for each treatment over all 20 periods. The random effects model included total effort as the dependent variable and a constant and a time trend as the independent variables. The model included random efforts error structure (individual subjects) and the standard errors were clustered at the session level. A standard Wald test, conducted on the estimates of the model, finds that for all treatments the constant coefficients are significantly higher than the predicted theoretical values ( $p$-value $<0.01$ ). The detailed estimation results are available from the authors upon request.

${ }^{12}$ It is important to emphasize that total effort is more stable in the LI treatment than in the HI or H treatments. When regressing total effort on a constant and a time trend, we find that the time trend is significant in the $\mathrm{HI}$ and $\mathrm{H}$ treatments ( $\mathrm{p}$-value $<0.01$ ), but it is not significant in the LI treatment ( $\mathrm{p}$-value $=0.18$ ). This result makes intuitive sense. Because there is no strategic momentum in the LI treatment, it is easier for subjects to make their bids in rounds 2 and 3. In the $\mathrm{HI}$ and $\mathrm{H}$ treatments, on the other hand, incentives inherent in the strategic momentum render bidding to be more complicated and thus it took more time for the behavior to stabilize.
} 
in proportion to the predicted level. Also, contrary to the prediction of a substantial drop in effort by round 1 loser, we find that both round 1 winner and loser increase their effort in round 2 . This over-dissipation in round 2 efforts by both players can explain why equilibrium over-predicts the probability of the contest ending in two rounds (HI: 63 versus 58 percent and H: 75 versus 61 percent).

There are a number of other explanations for over-dissipation in contests. One common explanation is that subjects are likely to make mistakes. Sheremeta (2011) shows how quantal response equilibrium (McKelvey and Palfrey, 1995), which accounts for individual errors, can explain some of the over-dissipation observed in lottery contests. Another explanation for overdissipation is based on the evolutionary argument (Leininger, 2003; Hehenkamp et al., 2004; Riechmann, 2007; Mago et al., 2012). Evolutionary behavior postulates that players aim to beat each other, i.e., the tenet of 'rational payoff maximization' is replaced by 'relative payoff maximization.' Theoretically, for a two-player single-round Tullock contest, the effort in an evolutionary stable equilibrium is twice the effort in the Nash equilibrium (Hehenkamp et al., 2004). ${ }^{13}$ Empirically, Mago et al. (2012) provide evidence for such behavior.

Another oft-cited explanation is based on judgmental biases and misperception of probabilities (Baharad and Nitzan, 2008). Many studies on individual behavior provide evidence that subjects misperceive probabilities in a systematic way - they assign over-weight to lower probability of winning and under-weight to higher probability of winning (Tversky and Kahneman, 1992). This misperception and the resulting errors are explored by Parco et al. (2005) and Amaldoss and Rapoport (2009) as an explanation for observed deviations from Nash equilibrium play in lottery contests. Finally, recent experiments have found evidence that

\footnotetext{
${ }^{13}$ This quest to seek higher (expected) payoff than others is consistent with 'spite effect' contended by Hamilton (1970) or 'survival of the fittest' contended by Alchian (1950). Vriend (2000) and Reichmann (2006) show that learning by imitation of successful others is also equivalent to maximizing relative payoffs.
} 
subjects have a non-monetary utility of winning a Tullock contest, and this can partially explain overdissipation of effort (Parco et al., 2005; Sheremeta, 2010b). ${ }^{14}$

All the above arguments can at least partially explain the over-dissipation documented in Result 6. However, we also provide an additional explanation for over-dissipation that is specific to our experiment: the sunk costs hypothesis. In an economic analysis of best-of-three contests, effort expenditures in earlier rounds are sunk costs. Therefore, rational subjects should not let these previous expenditures affect their effort choices in current rounds. Evidence from various behavioral studies, however, suggests sunk costs can affect behavior (Arkes and Blumer, 1985;

Friedman et al. 2010). ${ }^{15}$ In our experiment, subjects who get to the third round have already expended some positive effort in the previous two rounds. If the sunk costs hypothesis is true, subjects who expend more effort in rounds 1 and 2 are also more likely to expend higher effort in the final decisive round. Based on a simple random effect regression, we find that there is a positive and significant relation between effort in round 3 and total effort in the previous two rounds. This holds true irrespective of whether we use aggregate or treatment-specific data. Therefore, the sunk costs hypothesis may partially account for over-dissipation in our experiment.

\subsection{Heterogeneous Behavior}

Contrary to a unique pure-strategy Nash prediction, there is substantial variation in effort choices across subjects. In the HI treatment, total effort is predicted to be 50.5 , but instead the

\footnotetext{
${ }^{14}$ Sheremeta (2010b) provides evidence for such non-monetary utility, by documenting that about $50 \%$ of subjects are willing to exert positive effort (thereby incurring monetary costs) in order to be the winner of a contest with the prize value of 0 . Parco et al. (2005) conjecture that utility of winning is increasing in the size of the prize. This implies that intermediate prizes will render effort in $\mathrm{HI}$ treatment to be higher than effort in $\mathrm{H}$ treatment. This is borne by our comparative statics results (Result 1 ).

${ }^{15}$ In the literature, the mechanism underlying this 'irrational escalation of commitment' is attributed to cognitive dissonance (Festinger, 1957), self-justification (Aronson, 1968) and prospect theory or loss aversion (Tversky and Kahneman, 1979).
} 
individual average total effort choices range from 24.5 to 131.3 , with the standard deviation of 21.2. In the $H$ treatment, instead of predicted 32.0, the individual effort choices range from 11.3 to 127.9 , with the standard deviation of 24.4. Finally, in the LI treatment, instead of predicted 21.3, the individual effort choices range from 26.5 to 102.4 , with the standard deviation of 17.6.

Result 7: There is strong heterogeneity in effort between subjects.

A common explanation is that individual efforts are heterogeneous because subjects who make these effort choices have heterogeneous preferences (Sheremeta, 2013). We postulate that, to some extent, heterogeneity of efforts in our experiment can be explained by heterogeneity of individual risk preferences. ${ }^{16}$ Recall that in the first part of our experiment, subjects participated in a simple lottery choice experiment that measured risk aversion. The experiment contained 15 lottery choices - subjects were asked to state whether they preferred safe option A or risky option B. Option A yielded \$1 payoff with certainty, while option B yielded a payoff of either $\$ 3$ or $\$ 0$. The probability of receiving $\$ 3$ or $\$ 0$ varied across all 15 lotteries. ${ }^{17}$ These probabilities were structured such that the higher number of safe options corresponds to higher risk aversion. Our subject pool is typical in the sense that there is significant heterogeneity of risk preferences among subjects and a majority of subjects show a tendency towards risk-averse behavior (HI: 72 percent, H: 77.9 percent; LI: 76.2 percent).

Another factor that can explain the observed heterogeneity of efforts in contests is gender. It is well documented that women tend to overbid in auctions (Ham and Kagel, 2006;

\footnotetext{
${ }^{16}$ In the theoretical literature, the effect of risk aversion on effort in contests is ambiguous and depends on the assumptions of the model. Hillman and Katz (1984) showed that risk-averse players should expend lower effort than risk-neutral players, and risk-seeking players should exert higher effort. Treich (2009) established that risk aversion always reduces effort if risk-averse players are also 'prudent'. Nitzan (1991) showed that if agents are risk-averse, the degree of under-dissipation is inversely related to the degree of risk aversion. Konrad and Schlesinger (1997), on the other hand, showed that "it is possible for the contest with risk-averse players to dissipate more of the rents than the same contest with risk-neutral players" (Konrad and Schlesinger, 1997, p. 1677).

${ }^{17}$ The first lottery offered a $0 \%$ chance of winning $\$ 3$ and a $100 \%$ chance of winning $\$ 0$, while the last lottery offered a $70 \%$ chance of winning $\$ 3$ and a $30 \%$ chance of winning $\$ 0$.
} 
Charness and Levin, 2009; Chen et al., 2012). Price and Sheremeta (2012) find that, similarly to auction studies, women tend to make higher efforts (overbid) in contests. At the end of our experiment, we conducted a short demographic survey which contained gender information. According to the survey, there are about $40 \%$ of men and $60 \%$ of women in our sample.

We test for the effect of risk-aversion and gender on subjects' effort choices. Table 6 reports the estimation results of panel models where individual subjects represent the random effects, and the standard errors are clustered at the session level. The dependent variable in all specifications is the subject's total effort in the three rounds and the independent variables are a dummy-variable for woman, a number of safe choices, a period trend and a constant. The estimation results in specifications (1) and (2) indicate that women make significantly higher efforts in the $\mathrm{H}$ and $\mathrm{HI}$ treatments. This finding is consistent with the findings of Price and Sheremeta (2012). Specifications (1) and (2) also show a significant negative correlation between the total effort and the number of safe choices, thereby indicating that risk-averse subjects expend less effort. ${ }^{18}$ This observation is consistent with the findings of other contest experiments where $r=1$ (Millner and Pratt, 1991; Anderson and Freeborn, 2009; Sheremeta, 2011). Together, these findings suggest that gender and differences in risk preferences can partially explain heterogeneous behavior of subjects in contests. ${ }^{19}$

\footnotetext{
${ }^{18}$ It is interesting to note that neither gender nor risk preference are correlated with the total effort in the LI treatment. This can be explained by the fact that luck plays a relatively large role in the LI treatment, which diminishes the impact of risk preferences on total effort.

${ }^{19}$ We re-estimated the regressions reported in Table 3, controlling for gender and risk preferences, and found very similar treatment effects. When using the combined data for treatments $\mathrm{HI}$ and $\mathrm{H}$ (specification 1 in Table 3 ), gender and risk preferences are significantly correlated with total effort at the 0.01 level, but this does not hold true when we use the combined data for treatments HI and LI (specification 2). The probability of the contest ending in 2 rounds is also not affected by gender or risk preferences (specifications 3 and 4). Re-estimation of Table 5, controlling for gender and risk preferences, also yields very similar treatment effects. Moreover, due to more variability, effort in rounds 2 and 3 is not significantly correlated with gender or risk preferences. All results are available from authors upon request.
} 


\section{Conclusion}

In this paper, we use controlled laboratory environment to investigate the pattern of outcomes and efforts in a best-of-three contest that includes both intermediate prizes and a varying role of luck. Consistent with the theoretical predictions, we find that instituting intermediate prizes increases both the individual effort and the length of the contest. Conversely, players are unwilling to expend higher effort when luck plays a greater role in determining the winner. Our experimental design also disentangles the behavioral explanations of various effort choices from the strategic incentives. We observe strategic momentum in situations for which it is predicted, and we do not observe psychological momentum.

Our experiment provides direct empirical evidence that can be instructive in the design of optimal contests. Contest design has been a topic of extensive theoretical and empirical investigation primarily because contest objectives vary greatly - contests can be designed to generate highest revenue or to minimize social waste. For instance, in organization of sports tournaments it is often desirable to induce the players to spend the maximal amount of effort, or to induce an effort allocation that increases the chance of a close contest, with the objective of enhancing the excitement level of the tournament. Our experimental results indicate that this is best achieved by instituting intermediate prizes, and by making the contest more deterministic (i.e., reduce the random extraneous factors such as luck in determining the winner). In other rent seeking activities, such as political campaigns and patent races, the objective might be to minimize long-drawn contests and the accompanying wasteful expenditure. We find that it is best achieved by implementing only the grand prize (e.g., in U.S primaries, only the candidate to win a majority of their party delegates wins the party nomination; or in a patent race, only the first firm to finish the invention discovery process is awarded patent protection). 
To simplify the exposition we abstract from a number of issues that are nevertheless important in the field. For instance, we assume that there are only two players, and that they are symmetric. However, qualitative predictions of model do not change substantially when there are more than two players (Klumpp and Polborn, 2006). Furthermore, if one player has an exogenous advantage over the other, the ex ante advantage adds to the strategic momentum and further increases the probability of win by the skilled player.

Finally, although the focus of this paper has been comparative statics and pattern of effort, our results show that over-dissipation in contests is a robust phenomenon and is worthy of further investigation. We conjecture that best-of-three contests can provide a good platform for an explicit evaluation of some of the possible explanations for over-dissipation discussed above. This would involve both theoretical and experimental analysis. Theoretical work may be aimed at explaining the descriptive limitations of Nash equilibrium in these contests. For example, it may be possible to derive an evolutionary stable equilibrium for the entire best-of-three contest. Experimental investigation can then compare the predictions of this model to predictions based on the various competing explanations for over-dissipation. 


\section{References}

Alchian, A. (1950). Uncertainty, evolution and economic theory. Journal of Political Economy, $58,211-221$.

Amaldoss, W., \& Rapoport, A. (2009). Excessive Expenditure in Two-Stage Contests: Theory and Experimental Evidence. In I. N. Hangen and A. S. Nilsen (Eds.), Game Theory: Strategies, Equilibria and Theorems , 241-266, Nova Science Publishers, NY.

Anderson, L.R., \& Freeborn, B.A. (2010). Varying the intensity of competition in a multiple prize rent seeking experiment. Public Choice, 143, 237-254.

Anderson, L.R., and Stafford, S.L. (2003). An experiment analysis of rent seeking under varying competitive conditions. Public Choice, 115, 199-216.

Arkes, H.R., \& Blumer, C. (1985). The psychology of sunk cost. Organizational Behavior and Human Decision Processes, 35, 124-140.

Aronson, E. (1968). Dissonance Theory: Progress and Problems. In R. Abelson et al., eds, Theories of Cognitive Consistency: A Sourcebook, Rand McNally and Co, 5-27.Baharad, E., and Nitzan, S. (2008). Contest Efforts in Light of Behavioral Considerations. Economic Journal, 118, 2047-2059.

Baharad, E. \& Nitzan, S. (2008). Contest Efforts in Light of Behavioural Considerations. Economic Journal, 118, 2047-2059.

Baker, G., Gibbs, M., \& Holmstrom, B. (1994a). The Internal Economics of the Firm: Evidence from Personnel Data. Quarterly Journal of Economics, 109, 881-919.

Baker, G., Gibbs, M., \& Holmstrom, B. (1994b). The Wage Policy of a Firm. Quarterly Journal of Economics, 109, 921-955.

Cason, T. N., Masters, W.A., \& Sheremeta, R.M. (2010). Entry into Winner-Take-All and Proportional-Prize Contests: An Experimental Study. Journal of Public Economics, 94, 604611.

Cason, T.N., Sheremeta, R.M., \& Zhang, J. (2012). Communication and Efficiency in Competitive Coordination Games. Games and Economic Behavior, 76, 26-43.

Charness, G., \& Levin, D. (2009). The Origins of the Winner's Curse: A Laboratory Study. American Economic Journal: Microeconomics, 1, 207-36.

Chen, Y., Katuscak, P., \& Ozdenoren, E. (2012). Why Can't a Woman Bid More Like a Man? Games and Economic Behavior, forthcoming.

D’Avolio, G. (2002). The Market for Borrowing Stock. Journal of Financial Economics, 66, 271-306.

Davis, D., \& Reilly, R. (1998). Do too many cooks spoil the stew? An experimental Analysis of rent-seeking and the role of a strategic buyer. Public Choice, 95, 89- 115.

Dechenaux, E., Kovenock, D., \& Sheremeta, R.M. (2012). A Survey of Experimental Research on Contests, All-Pay Auctions and Tournaments. Chapman University, ESI Working Paper.

Deck, C., \& Sheremeta, R.M. (2012). Fight or Flight? Defending Against Sequential Attacks in the Game of Siege. Journal of Conflict Resolution, 56, 1069-1088.

Dorsey-Palmateer, R., \& Smith, G. (2004). Bowlers' hot hands. American Statistician, 58, 38-45.

Ferrall, C., \& Smith, A. (1999). A sequential game model of sports championship series: theory and estimation. Review of Economics and Statistics, 81, 704-719.

Festinger, L. (1957). A Theory of Cognitive Dissonance. Stanford: Stanford University Press.

Fischbacher, U. (2007). z-Tree: Zurich Toolbox for Ready-made Economic experiments. Experimental Economics, 10, 171-178. 
Fonseca, M.A. (2009). An experimental investigation of asymmetric contests. International Journal of Industrial Organization, 27, 582-591.

Freeman, R.B., \& Gelber, A.M. (2010). Prize Structure and Information in Tournaments: Experimental Evidence. American Economic Journal: Applied Economics, 2, 149-64.

Friedman, D., Pommerenke, K., Lukose, R., Milam, G., \& Huberman, B.A. (2010). In search for the sunk cost fallacy. Experimental Economics, 10, 79-104

Fudenberg, D., Gilbert, R., Stiglitz, J., \& Tirole, J. (1983). Preemption, leapfrogging and competition in patent races. European Economic Review, 22, 3-31.

Ham, J.C., \& Kagel, J.H. (2006). Gender Effects in Private Value Auctions. Economic Letters, 92, 375-382.

Hamilton, W.D. (1970). Selfish and spiteful behavior in evolutionary model. Nature, 228, 12181220.

Hehenkamp, B., Leininger, W., \& Possajenikov, A. (2004). Evolutionary equilibrium in Tullock contests: spite and overdissipation. European Journal of Political Economy, 20, 1045-1057.

Hillman, A.L. \& Katz, E. (1984). Risk averse rent-seekers and the social cost of monopoly power. Economic Journal, 94, 104-110.

Holt, C. A. and Laury, S. (2002). Risk Aversion and Incentive Effects. American Economic Review , 92,1644-1655.

Irfanoglu, Z.B., Mago, S.D., \& Sheremeta, R.M. (2013). Sequential versus Simultaneous Election Contests: An Experimental Study. Chapman University, ESI Working Paper.

Jackson, D. (1993). Independent trials are a model for disaster. Applied Statistics, 42, 211-220.

Kerick, S.E., Iso-Ahola, S.E. \& Hatfield, B.D. (2000). Psychological momentum in target shooting: Cortical, cognitive-affective, and behavioral responses. Journal of Sport \& Exercise Psychology, 22, 1-20.

Kimbrough, E.O., \& Sheremeta, R.M. (2012). Side-Payments and the Costs of Conflict. International Journal of Industrial Organization, forthcoming.

Klumpp, T., \& Polborn, M.K. (2006). Primaries and the New Hampshire effect. Journal of Public Economics, 90, 1073-1114.

Konrad, K. A., \& Schlesinger, H. (1997). Risk aversion in risk seeking and rent-augmenting games. Economic Journal, 107, 1671-1683.

Konrad, K.A., \& Kovenock, D. (2009). Multi-battle contests. Games and Economic Behavior, 66, 256-274.

Leininger, W. (2003). On evolutionarily stable behavior in contests. Economics of Governance, 4, 177-186.

Mago, S.D., \& Sheremeta, R.M. (2012). Multi-battle Contests: An Experimental Study. Chapman University, ESI Working Paper.

Mago, S.D., Savikhin, A.C., \& Sheremeta, R.M. (2012). Facing Your Opponents: Social Identification and Information Feedback in Contests. Chapman University, ESI Working Paper.

Malueg, D., \& Yates, A. (2005). Equilibria and comparative statics in two player contests. European Journal of Political Economy, 21, 738-752.

Malueg, D., \& Yates, A. (2010). Testing contest theory: evidence from best-of-three tennis matches. Review of Economics and Statistics, 92, 689-692.

McFall, T., Knoeber, C., \& Thurman, W. (2009). Contests, grand prizes, and the hot hand. Journal of Sports Economics, 10, 236-255. 
McKee, M. (1989). Intra-experimental income effects and risk aversion. Economic Letters, 30, 109-115.

McKelvey, R. \& Palfrey, T. (1995). Quantal Response Equilibria for Normal Form Games. Games and Economic Behavior, 10, 6-38.

Millner, E. L. \& Pratt, M. (1991). Risk Aversion and Rent-Seeking: An Extension and Some Experimental Evidence. Public Choice, 69, 81-92.

Millner, E.L. \& Pratt, M.D. (1989). An Experimental Investigation of Efficient Rent-Seeking. Public Choice, 62, 139-151.

Mosteller, F. (1952). The world series competition. Journal of the American Statistical Association, 47, 355-380.

Nitzan, S. (1991). Collective Rent Dissipation. The Economic Journal, 101, 1522-1534.

Parco J., Rapoport A., \& Amaldoss W. (2005). Two-stage Contests with Budget Constraints: An Experimental Study. Journal of Mathematical Psychology, 49, 320-338.

Potters, J., de Vries, C.G., \& van Winden, F. (1998). An experimental examination of rational rent-seeking. European Journal of Political Economy, 14, 783 - 800.

Price, C.R. \& Sheremeta, R.M. (2011). Endowment Effects in Contests. Economics Letters, 111, 217-219.

Price, C.R., \& Sheremeta, R.M. (2012). Endowment Origin, Demographic Effects and Individual Preferences in Contests. Chapman University, ESI Working Paper.

Riechmann, T. (2007). An analysis of rent-seeking games with relative-payoff maximizers. Public Choice, 133, 147-155.

Savikhin, A.C. \& Sheremeta, R.M. (2012). Simultaneous Decision-Making in Competitive and Cooperative Games. Economic Inquiry, forthcoming.

Schmitt, P., Shupp, R. Swope, K., \& Cadigan, J. (2004). Multi-period rent-seeking contests with carryover: Theory and Experimental Evidence. Economics of Governance, 10, 247-259.

Sheremeta, R.M. (2010a). Expenditures and Information Disclosure in Two-Stage Political Contests. Journal of Conflict Resolution, 54, 771-798.

Sheremeta, R.M. (2010b). Experimental Comparison of Multi-Stage and One-Stage Contests. Games and Economic Behavior, 68, 731-747.

Sheremeta, R.M. (2011). Contest Design: An Experimental Investigation. Economic Inquiry, 49, 573-590.

Sheremeta, R.M. (2013). Overbidding and Heterogeneous Behavior in Contest Experiments. Chapman University, ESI Working Paper.

Sheremeta, R.M., \& Zhang, J. (2010). Can Groups Solve the Problem of Over-Bidding in Contests? Social Choice and Welfare, 35, 175-197.

Szymanski, S. (2003). The Economic Design of Sporting Contests, Journal of Economic Literature, 41, 1137-1187.

Treich, N. (2009). Risk-aversion and prudence in rent-seeking games. Public Choice, 1573-7101.

Tullock, G. (1980). Efficient Rent Seeking. In James M. Buchanan, Robert D. Tollison, Gordon Tullock, (Eds.), Toward a theory of the rent-seeking society. College Station, TX: Texas A\&M University Press, pp. 97-112.

Tversky, A. \& Kahneman, D. (1992). Advances in Prospect Theory: Cumulative Representation of Uncertainty. Journal of Risk and Uncertainty, 5, 297-323.

Tversky, A., \& Kahneman, D. (1974). Judgment under uncertainty: Heuristics and biases. Science, 185, 1124-1130. 
Vallerand, R. J., Colavecchio, P. G., \& Pelletier, L. G. (1988). Psychological momentum and performance inferences: a preliminary test of the antecedents-consequences psychological momentum model. Journal of Sport and Exercise Psychology, 10, 92-108.

van Dijk, F., Sonnemans, J., \& van Winden, F. (2001). Incentives Systems in a Real Effort Experiment. European Economic Review, 45, 187-214.

Vriend, N.J. (2000). An illustration if the essential difference between individual and social learning, and its consequences for computational analyses. Journal of Economic Dynamics and Control, 24, 1-19.

Zizzo, D.J. (2002). Racing with Uncertainty: A Patent Race Experiment. International Journal of Industrial Organization, 20, 877-902. 
Table 1: Experimental Design and Predictions

\begin{tabular}{lccc}
\hline \hline Treatments & $\mathrm{H}$ & $\mathrm{HI}$ & $\mathrm{LI}$ \\
\hline Final prize, $v$ & 100 & 100 & 100 \\
Intermediate prize, $d$ & 0 & 25 & 25 \\
Exponent, $r$ & 1 & 1 & 0.4 \\
\hline Equilibrium predictions & & & \\
\hline Effort in R1 & 16.4 & 21.2 & 7.5 \\
Effort in R2 by R1 winner & 14.1 & 22.0 & 7.5 \\
Effort in R2 by R1 loser & 4.7 & 13.2 & 7.5 \\
Effort in R3 by R2 winner & 25.0 & 31.3 & 12.5 \\
Effort in R3 by R2 loser & 25.0 & 31.3 & 12.5 \\
The probability of ending in R2 & 0.75 & 0.63 & 0.5 \\
Expected average effort & 32.0 & 50.5 & 21.3 \\
Expected payoff & 18.0 & 29.2 & 60.0 \\
\hline
\end{tabular}

Table 2: Summary Statistics

\begin{tabular}{|c|c|c|c|c|c|c|}
\hline Treatments & \multicolumn{2}{|c|}{$\mathrm{H}$} & \multicolumn{2}{|c|}{ HI } & \multicolumn{2}{|c|}{ LI } \\
\hline Final prize, $v$ & \multicolumn{2}{|c|}{100} & \multicolumn{2}{|c|}{100} & \multicolumn{2}{|c|}{100} \\
\hline Intermediate prize, $d$ & \multicolumn{2}{|c|}{0} & \multicolumn{2}{|c|}{25} & \multicolumn{2}{|c|}{25} \\
\hline Exponent, $r$ & \multicolumn{2}{|c|}{1} & \multicolumn{2}{|c|}{1} & \multicolumn{2}{|c|}{0.4} \\
\hline & Equilibrium & Actual & Equilibrium & Actual & Equilibrium & Actual \\
\hline Effort in R1 & 16.4 & $22.2(16.3)$ & 21.2 & $27.2(15.8)$ & 7.5 & $22.3(10.5)$ \\
\hline Effort in $\mathrm{R} 2$ by $\mathrm{R} 1$ winner & 14.1 & $28.5(16.8)$ & 22.0 & $37.0(18.4)$ & 7.5 & $24.4(11.1)$ \\
\hline Effort in R2 by R1 loser & 4.7 & $23.5(19.1)$ & 13.2 & $28.1(16.2)$ & 7.5 & $23.3(11.3)$ \\
\hline Effort in R3 by R2 winner & 25.0 & $33.2(18.2)$ & 31.3 & $40.6(16.9)$ & 12.5 & $25.3(11.9)$ \\
\hline Effort in R3 by R2 loser & 25.0 & $31.7(17.2)$ & 31.3 & $38.1(16.5)$ & 12.5 & $24.3(10.5)$ \\
\hline The probability of ending in $\mathrm{R} 2$ & 0.75 & $0.61(0.49)$ & 0.63 & $0.58(0.49)$ & 0.50 & $0.51(0.50)$ \\
\hline Expected average effort & 32.0 & $60.8(39.6)$ & 50.5 & $76.3(39.3)$ & 21.3 & $58.2(26.7)$ \\
\hline Expected payoff & 18.0 & $-10.9(56.7)$ & 29.2 & $4.0(71.2)$ & 60.0 & $22.9(71.4)$ \\
\hline
\end{tabular}

The standard deviations are in parentheses.

Table 3: Panel Estimation Testing Hypotheses 1 and 2

\begin{tabular}{lcccc}
\hline \hline Dependent variable & total effort & total effort & $\begin{array}{c}\text { ending in } \\
\text { 2 rounds }\end{array}$ & $\begin{array}{c}\text { ending in } \\
\text { 2 rounds }\end{array}$ \\
\hline Treatments & HI versus H & HI versus LI & HI versus H & HI versus LI \\
\hline Specification & $(1)$ & $(2)$ & $(3)$ & $(4)$ \\
\hline period & $45.01 * * *$ & $23.41 * * *$ & $-0.48^{* * *}$ & -0.23 \\
$\quad$ inverse period trend] & $(6.06)$ & $(8.26)$ & $(0.15)$ & $(0.15)$ \\
treatment HI & $15.42^{* * *}$ & $18.13 * * *$ & -0.08 & $0.17 * *$ \\
$\quad 1$ if treatment is HI] & $(5.13)$ & $(4.95)$ & $(0.07)$ & $(0.07)$ \\
constant & $52.76 * * *$ & $53.94 * * *$ & $0.37 * * *$ & 0.08 \\
& $(4.67)$ & $(5.00)$ & $(0.06)$ & $(0.06)$ \\
\hline Observations & 1,440 & 1,440 & 1,440 & 1,440 \\
\hline$*$ significant at 10\%, ** significant at 5\%, *** significant at $1 \%$. The standard errors are \\
in parentheses. All models include a random effects error structure, with the individual \\
subject as the random effect, to account for the multiple decisions made by the subject.
\end{tabular}


Table 4: Panel Estimation Testing Hypothesis 3

\begin{tabular}{lcccccc}
\hline \hline Dependent variable & $\begin{array}{c}\text { effort3- } \\
\text { effort1 }\end{array}$ & $\begin{array}{c}\text { effort3- } \\
\text { effort1 }\end{array}$ & $\begin{array}{c}\text { effort3- } \\
\text { effort1 }\end{array}$ & $\begin{array}{c}\text { effort3- } \\
\text { effort2 }\end{array}$ & $\begin{array}{c}\text { effort3- } \\
\text { effort2 }\end{array}$ & $\begin{array}{c}\text { effort3- } \\
\text { effort2 }\end{array}$ \\
\hline Treatment & $\mathrm{H}$ & $\mathrm{HI}$ & $\mathrm{LI}$ & $\mathrm{H}$ & $\mathrm{HI}$ & $\mathrm{LI}$ \\
\hline Specification & $(1)$ & $(2)$ & $(3)$ & $(4)$ & $(5)$ & $(6)$ \\
\hline period & -3.34 & 6.16 & $-6.10^{*}$ & $-3.53^{* *}$ & 5.39 & $-6.19^{* *}$ \\
$\quad$ inverse period trend] & $(4.30)$ & $(8.45)$ & $(3.43)$ & $(1.70)$ & $(5.64)$ & $(2.63)$ \\
constant & $10.46^{* * *}$ & $11.28^{* * *}$ & $3.42^{* * *}$ & $4.71^{* * *}$ & $5.10^{* * * *}$ & $2.41^{* * *}$ \\
& $(2.32)$ & $(3.06)$ & $(0.33)$ & $(0.66)$ & $(1.80)$ & $(0.20)$ \\
\hline Observations & 280 & 302 & 350 & 280 & 302 & 350 \\
\hline * significant at 10\%, ** significant at $5 \%, * * *$ significant at & $1 \%$. The standard errors are in \\
parentheses. All models include a random effects error structure, with the individual subject as \\
the random effect, to account for the multiple decisions made by the subject.
\end{tabular}

Table 5: Panel Estimation Testing Hypotheses 4 and 5

\begin{tabular}{|c|c|c|c|c|c|c|}
\hline Dependent variable & effort2 & effort2 & effort 2 & effort3 & effort3 & effort3 \\
\hline Treatment & $\mathrm{H}$ & $\mathrm{HI}$ & LI & $\mathrm{H}$ & $\mathrm{HI}$ & LI \\
\hline Specification & (1) & (2) & (3) & (4) & (5) & (6) \\
\hline $\begin{array}{l}\text { period } \\
\quad \text { [inverse period trend] }\end{array}$ & $\begin{array}{l}19.61 * * * \\
(2.54)\end{array}$ & $\begin{array}{l}12.42 * * * \\
(2.53)\end{array}$ & $\begin{array}{l}6.78 * * * \\
(1.42)\end{array}$ & $\begin{array}{c}17.81 * * * \\
(3.78)\end{array}$ & $\begin{array}{l}12.89 * * * \\
(3.58)\end{array}$ & $\begin{array}{l}-1.48 \\
(1.94)\end{array}$ \\
\hline $\begin{array}{l}\text { winl } \\
\quad[1 \text { if round } 1 \text { winner }]\end{array}$ & $\begin{array}{c}2.36^{* *} \\
(1.17)\end{array}$ & $\begin{array}{c}5.51 * * * \\
(1.17)\end{array}$ & $\begin{array}{c}0.82 \\
(0.63)\end{array}$ & & & \\
\hline $\begin{array}{l}\operatorname{win} 2 \\
\quad[1 \text { if round } 2 \text { winner] }\end{array}$ & & & & $\begin{array}{c}0.82 \\
(1.70)\end{array}$ & $\begin{array}{c}2.52 \\
(1.80)\end{array}$ & $\begin{array}{c}0.86 \\
(0.91)\end{array}$ \\
\hline constant & $\begin{array}{c}21.30 * * * \\
(1.73)\end{array}$ & $\begin{array}{c}27.57 * * * \\
(1.57)\end{array}$ & $\begin{array}{c}22.21 * * * \\
(1.35)\end{array}$ & $\begin{array}{c}28.92 * * * \\
(2.43)\end{array}$ & $\begin{array}{l}35.80 * * * \\
(1.99)\end{array}$ & $\begin{array}{l}24.70 * * * \\
(1.59)\end{array}$ \\
\hline Observations & 720 & 720 & 720 & 280 & 302 & 350 \\
\hline
\end{tabular}

Table 6: Panel Estimation for Risk and Gender

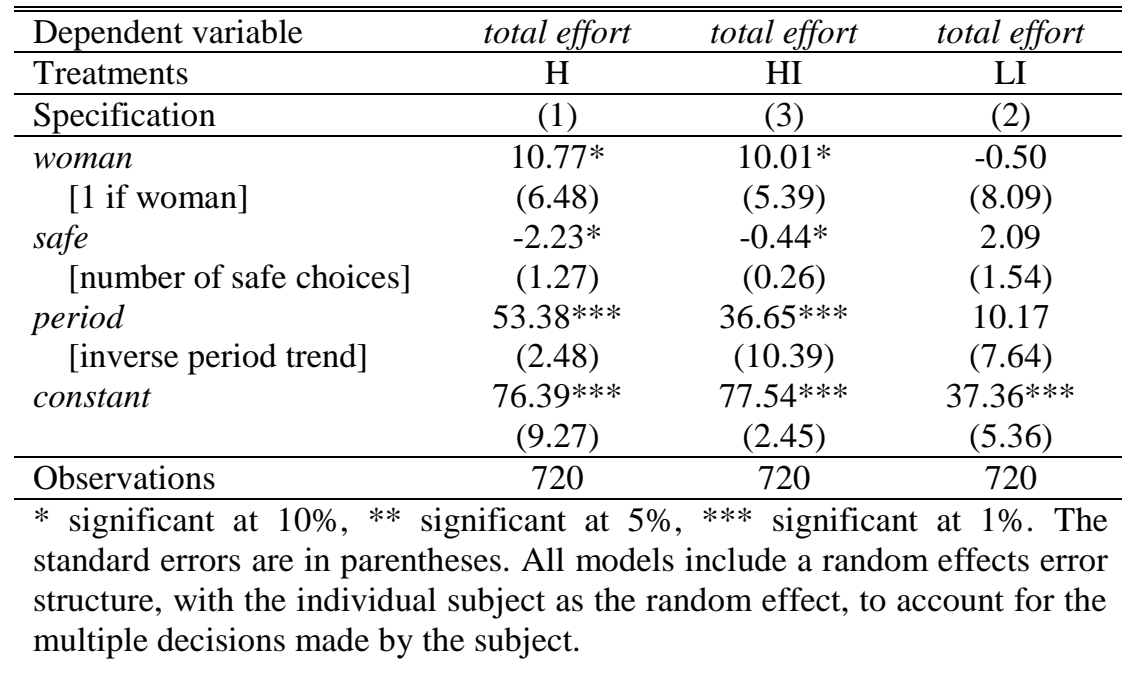


Figure 1: Total Effort over 20 Periods

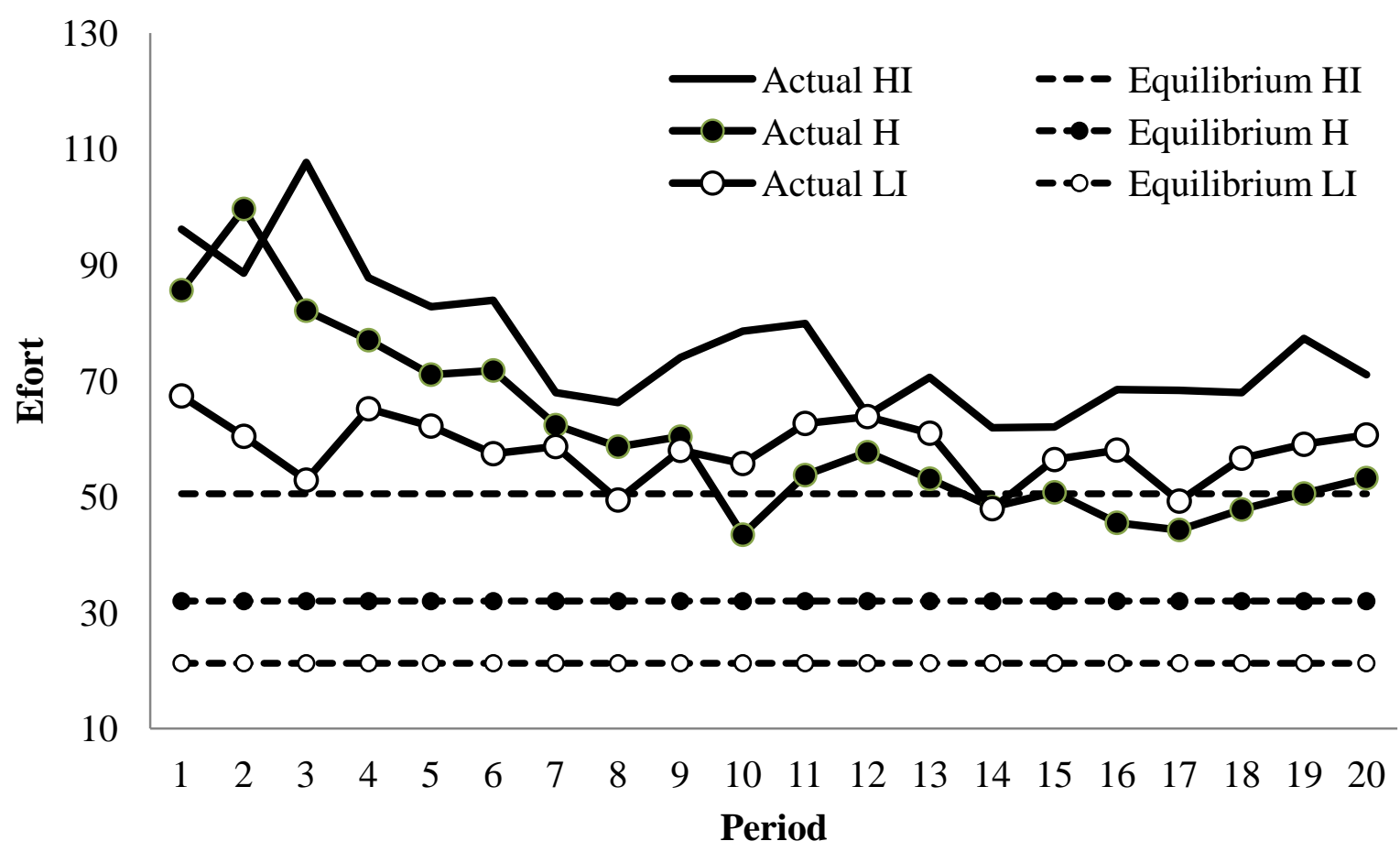

Figure 2: Effort in 3 Rounds over 20 Periods (HI Treatment)

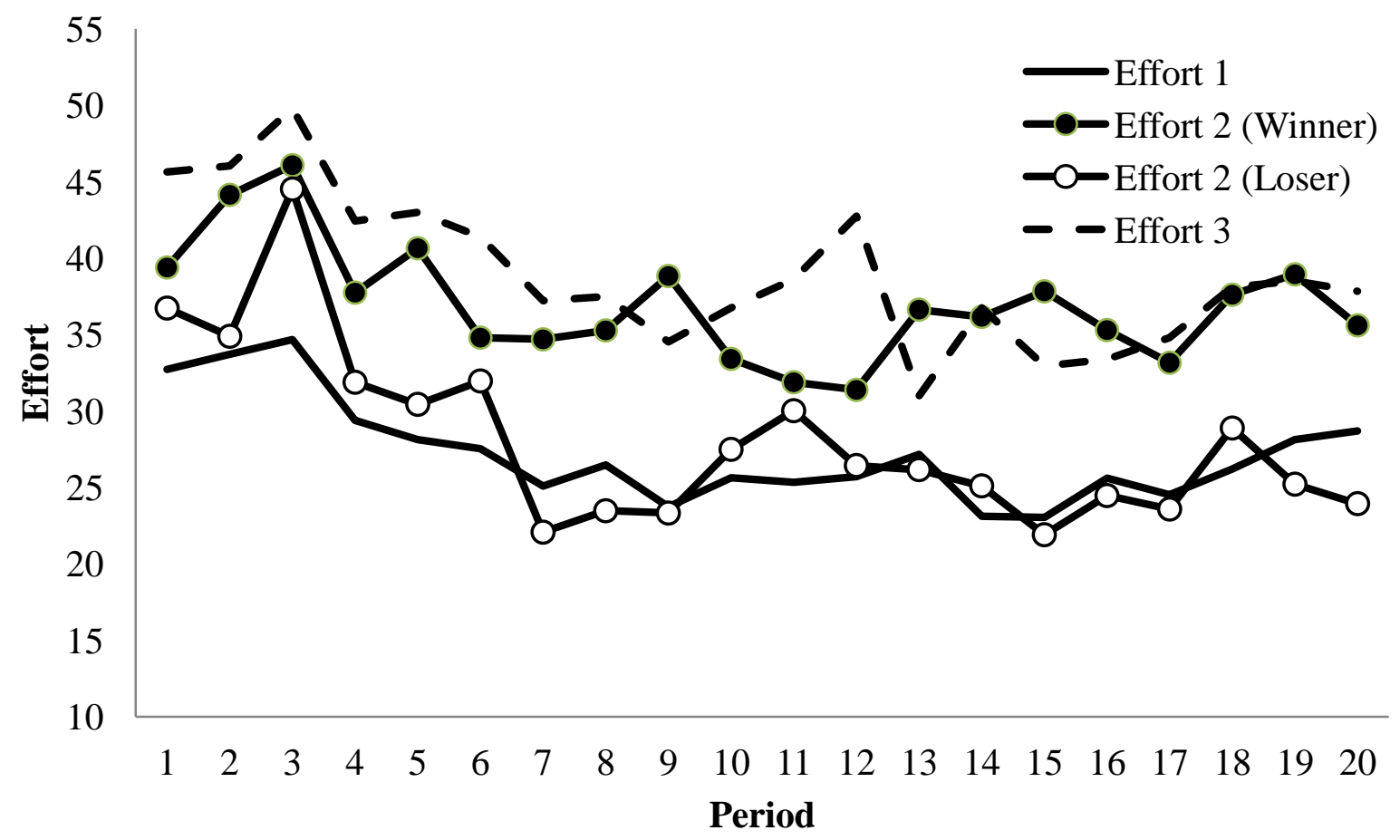




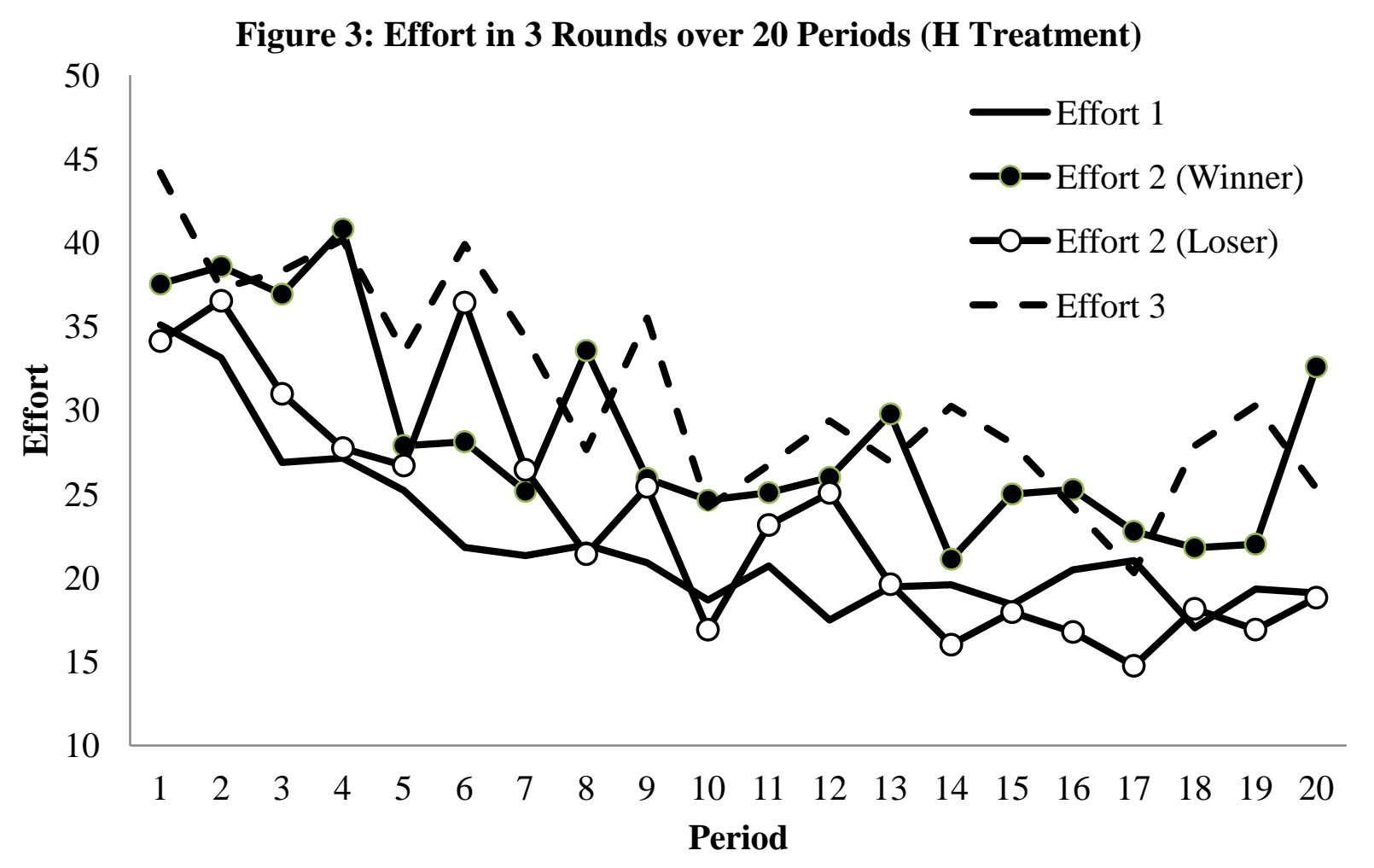

Figure 4: Effort in 3 Rounds over 20 Periods (LI Treatment)

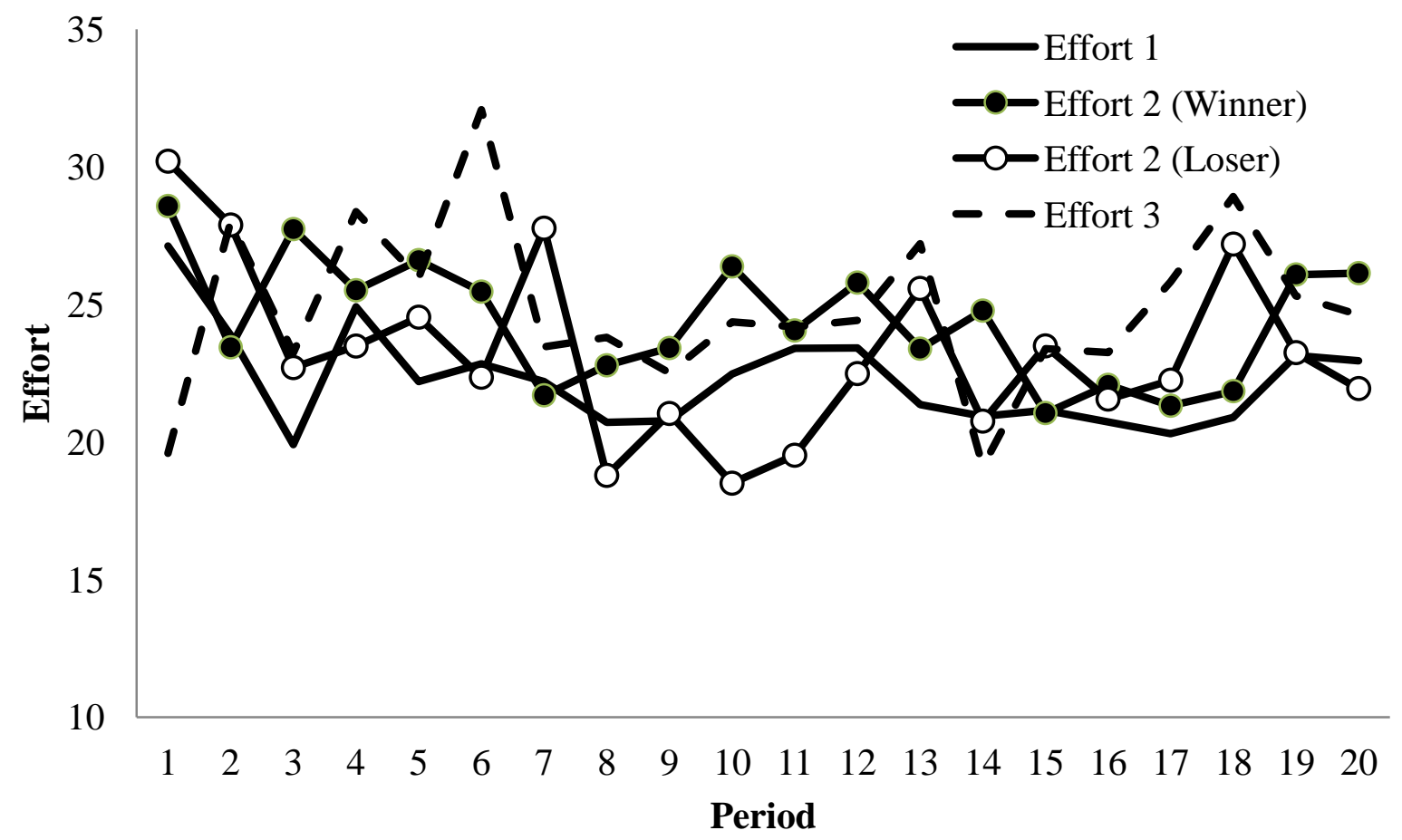




\section{Online Appendix: Instructions for HI Treatment}

\section{GENERAL INSTRUCTIONS}

This is an experiment in the economics of strategic decision making. Various research agencies have provided funds for this research. The instructions are simple. If you follow them closely and make appropriate decisions, you can earn an appreciable amount of money.

The experiment will proceed in two parts. Each part contains decision problems that require you to make a series of economic choices which determine your total earnings. The currency used in Part 1 of the experiment is U.S. Dollars. The currency used in Part 2 of the experiment is francs. These francs will be converted to U.S. Dollars at a rate of $\mathbf{2 5}$ francs to $\mathbf{1}$ dollar. You have already received a $\mathbf{\$ 2 0 . 0 0}$ participation fee (this includes your showup fee of \$7.00). Your earnings from both Part 1 and Part 2 of the experiment will be incorporated into your participation fee. At the end of today's experiment, you will be paid in private and in cash. There are $\mathbf{1 2}$ participants in today's experiment.

It is very important that you remain silent and do not look at other people's work. If you have any questions, or need assistance of any kind, please raise your hand and an experimenter will come to you. If you talk, laugh, exclaim out loud, etc., you will be asked to leave and you will not be paid. We expect and appreciate your cooperation.

\section{INSTRUCTIONS FOR PART 1}

In this part of the experiment you will be asked to make a series of choices in decision problems. How much you receive will depend partly on chance and partly on the choices you make. The decision problems are not designed to test you. What we want to know is what choices you would make in them. The only right answer is what you really would choose.

For each line in the table in the next page, please state whether you prefer option A or option B. Notice that there are a total of $\mathbf{1 5}$ lines in the table but only one line will be randomly selected for payment. Each line is equally likely to be selected, and you do not know which line will be selected when you make your choices. Hence you should pay attention to the choice you make in every line. After you have completed all your choices a token will be randomly drawn out of a bingo cage containing tokens numbered from 1 to 15. The token number determines which line is going to be selected for payment.

Your earnings for the selected line depend on which option you chose: If you chose option A in that line, you will receive $\mathbf{\$ 1}$. If you chose option B in that line, you will receive either $\mathbf{\$ 3}$ or $\mathbf{\$ 0}$. To determine your earnings in the case you chose option B there will be second random draw. A token will be randomly drawn out of the bingo cage now containing twenty tokens numbered from 1 to 20. The token number is then compared with the numbers in the line selected (see the table). If the token number shows up in the left column you earn $\$ 3$. If the token number shows up in the right column you earn $\$ 0$.

While you have all the information in the table, we ask you that you input all your 15 decisions into the computer. The actual earnings for this part will be determined at the end of part 2, and will be independent of part 2 earnings.

\begin{tabular}{|l||l||l|l||c|}
\hline $\begin{array}{l}\text { Deci } \\
\text { sion } \\
\text { no. }\end{array}$ & $\begin{array}{l}\text { Opti } \\
\text { on } \mathbf{A}\end{array}$ & \multicolumn{2}{|c||}{$\begin{array}{c}\text { Option } \\
\mathbf{B}\end{array}$} & $\begin{array}{c}\text { Please } \\
\text { choose } \\
\text { A or B }\end{array}$ \\
\hline 1 & $\mathbf{\$ 1}$ & $\mathbf{\$ 3}$ never & $\mathbf{\$ 0}$ if $1,2,3,4,5,6,7,8,9,10,11,12,13,14,15,16,17,18,19,20$ & \\
\hline 2 & $\mathbf{\$ 1}$ & $\mathbf{\$ 3}$ if 1 comes out of the bingo cage & $\mathbf{\$ 0}$ if $2,3,4,5,6,7,8,9,10,11,12,13,14,15,16,17,18,19,20$ & \\
\hline 3 & $\mathbf{\$ 1}$ & $\mathbf{\$ 3}$ if 1 or 2 & $\mathbf{\$ 0}$ if $3,4,5,6,7,8,9,10,11,12,13,14,15,16,17,18,19,20$ & \\
\hline 4 & $\mathbf{\$ 1}$ & $\mathbf{\$ 3}$ if $1,2,3$ & $\mathbf{\$ 0}$ if $4,5,6,7,8,9,10,11,12,13,14,15,16,17,18,19,20$ & \\
\hline 5 & $\mathbf{\$ 1}$ & $\mathbf{\$ 3}$ if $1,2,3,4$, & $\mathbf{\$ 0}$ if $5,6,7,8,9,10,11,12,13,14,15,16,17,18,19,20$ & \\
\hline 6 & $\mathbf{\$ 1}$ & $\mathbf{\$ 3}$ if $1,2,3,4,5$ & $\mathbf{\$ 0}$ if $6,7,8,9,10,11,12,13,14,15,16,17,18,19,20$ & \\
\hline 7 & $\mathbf{\$ 1}$ & $\mathbf{\$ 3}$ if $1,2,3,4,5,6$ & $\mathbf{\$ 0}$ if $7,8,9,10,11,12,13,14,15,16,17,18,19,20$ & \\
\hline 8 & $\mathbf{\$ 1}$ & $\mathbf{\$ 3}$ if $1,2,3,4,5,6,7$ & $\mathbf{\$ 0}$ if $8,9,10,11,12,13,14,15,16,17,18,19,20$ & \\
\hline 9 & $\mathbf{\$ 1}$ & $\mathbf{\$ 3}$ if $1,2,3,4,5,6,7,8$ & $\mathbf{\$ 0}$ if $\mathbf{9}, 10,11,12,13,14,15,16,17,18,19,20$ & \\
\hline 10 & $\mathbf{\$ 1}$ & $\mathbf{\$ 3}$ if $1,2,3,4,5,6,7,8,9$ & $\mathbf{\$ 0}$ if $10,11,12,13,14,15,16,17,18,19,20$ & \\
\hline 11 & $\mathbf{\$ 1}$ & $\mathbf{\$ 3}$ if $1,2,3,4,5,6,7,8,9,10$ & $\mathbf{\$ 0}$ if $11,12,13,14,15,16,17,18,19,20$ & $\mathbf{\$ 0}$ \\
\hline 12 & $\mathbf{\$ 1}$ & $\mathbf{\$ 3}$ if $1,2,3,4,5,6,7,8,9,10,11$ & $\mathbf{\$ 0}$ if $12,13,14,15,16,17,18,19,20$ & \\
\hline 13 & $\mathbf{\$ 1}$ & $\mathbf{\$ 3}$ if $1,2,3,4,5,6,7,8,9,10,11,12$ & $\mathbf{\$ 0}$ if $13,14,15,16,17,18,19,20$ \\
\hline 14 & $\mathbf{\$ 1}$ & $\mathbf{\$ 3}$ if $1,2,3,4,5,6,7,8,9,10,11,12,13$ & $\mathbf{\$ 0}$ if $14,15,16,17,18,19,20$ \\
\hline 15 & $\mathbf{\$ 1}$ & $\mathbf{\$ 3}$ if $1,2,3,4,5,6,7,8,9,10,11,12,13,14$ & $\mathbf{\$ 0}$ if $15,16,17,18,19,20$ \\
\hline
\end{tabular}




\section{INSTRUCTIONS FOR PART 2 \\ YOUR DECISION}

The second part of the experiment consists of $\mathbf{2 0}$ decision-making periods. The 12 participants in today's experiment will be randomly re-matched every period into 6 groups with 2 participants in each group. Therefore, the specific person who is the other participant in your group will change randomly after each period. The group assignment is anonymous, so you will not be told which of the participants in this room are assigned to your group

Each period consists of a maximum of three rounds. The period ends when one of the participants wins two of the three rounds ("best of three"). Thus, each period will consist of either two or three rounds. In each round, you and the other participant in your group will simultaneously make a bid (any number, including 0.1 decimal points). Your bid in each round cannot exceed 100 francs. The more you bid, the more likely you are to win a particular round. This will be explained in more detail later. Your earnings depend on the number of rounds you won and how many francs you spent on bidding. An example of your decision screen is shown below in Figure 1:

Figure 1 - Decision Screen

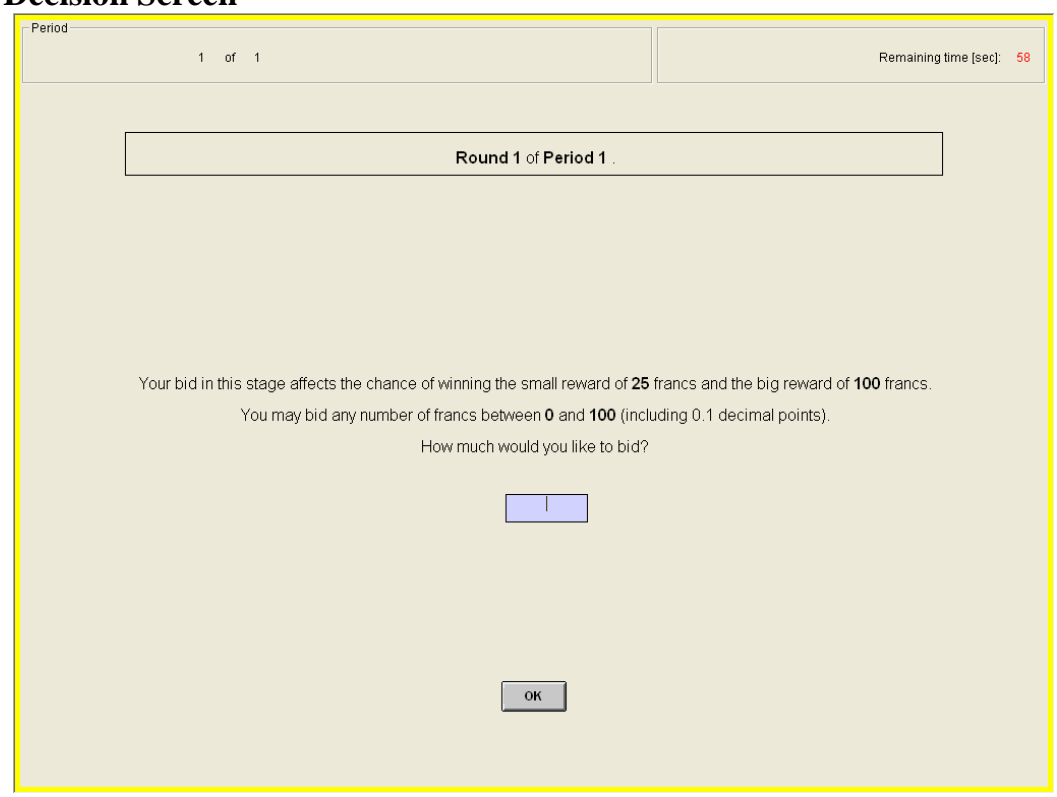

There are two types of rewards that you may receive during each period: big reward and small reward. The big reward is worth $\mathbf{1 0 0}$ francs and the small reward is worth $\mathbf{2 5}$ francs to you and the other participant in your group. The winner of an individual round will receive the small reward, while the participant who is first to win two rounds receives, in addition, the big reward. The period ends as soon as the big reward winner is determined.

\section{CHANCE OF WINNING A ROUND}

You can never guarantee that you will win a round. However, the greater your bid relative to the other participant's bid, the greater your probability of winning the round. That is, the more you bid, the more likely you are to win a round. The more the other participant in your group bids, the less likely you are to win a round. Specifically, your chance of winning a round is given by the following expression.

Your chance of (Your Bid)

winning a round $\quad=\quad($ Your Bid $)+($ The Other Participant's Bid $)$

Think of this in the following way. For each franc you bid you will receive lottery tickets. For example, if you bid 10 francs and the other participant bid 20 francs, you will receive 10 lottery tickets and the other participant will receive 20 lottery tickets. At the end of each round the computer draws randomly one ticket among all the tickets purchased by you and the other participant in your group. The owner of the drawn ticket wins the round. In the example above, your chance of winning the round is $0.33=10 /(10+20)$ and the other participant's chance of winning is $0.67=20 /(10+20)$. Note that your chance of winning a round is proportional to the amount of lottery tickets purchased by you and the other participant.

In the sheet attached to these instructions, you will find a probability table. This table will give you some idea of how your bid and the other participant's bid affect your chance of winning. For instance, suppose you bid 50 francs and the other participant bid 30 francs then your chance of winning the round is 0.63 . Note that as stated before, your chance of winning increases as your bid increases relative to the other participant's bid. So if you bid 
70 francs and the other participant is still bidding 30 francs, your chance of winning increases to 0.70 . To assist you with calculation of more precise numbers, we will provide you with the Excel calculator in each round. You may use the calculator to find the chance of winning for any combination of your bid and the other participant's bid. We will have a few practice rounds with the Excel calculator before the start of the experiment.

\section{YOUR EARNINGS}

Your earnings depend on the number of rounds you won and how many francs you spent on bidding in each round. For each round you win you receive a small reward. The participant who is first to win two rounds receives, in addition, the big reward. One of the four payment scenarios is possible:

(1) If the period lasted for only two rounds

(1a) Earnings of the participant who won both rounds are $=$ $=($ big reward $)+(2 \times$ small reward $)-($ bid in round 1$)-($ bid in round 2$)$

$=100+2 \times 25-($ bid in round 1$)-($ bid in round 2$)$

(1b) Earnings of the participant who won neither rounds are $=$ $=0-($ bid in round 1$)-($ bid in round 2$)$

(2) If the period lasted for three rounds

(2a) Earnings of the participant who won two rounds are $=$ $=($ big reward $)+(2 \times$ small reward $)-($ bid in round 1$)-($ bid in round 2$)-($ bid in round 3$)$

$=100+2 \times 25-($ bid in round 1$)-($ bid in round 2$)-($ bid in round 3$)$

(2b) Earnings of the participant who won one round are $=$ $=(1 \times$ small reward $)-($ bid in round 1$)-($ bid in round 2$)-($ bid in round 3$)$ $=1 \times 25-($ bid in round 1$)-($ bid in round 2$)-($ bid in round 3$)$

Please note that regardless of who wins the round, both participants will have to pay their bids.

\section{END OF THE ROUND}

After both participants make their round bids, the computer will make a random draw which will determine the winner of the round. Both participants will observe the outcome of the round - your bid, other participant's bid and winner, as shown in Figure 2. Then they make bids in another round. This continues until one of the participants in the group wins two rounds.

Figure 2 - Intermediate Screen

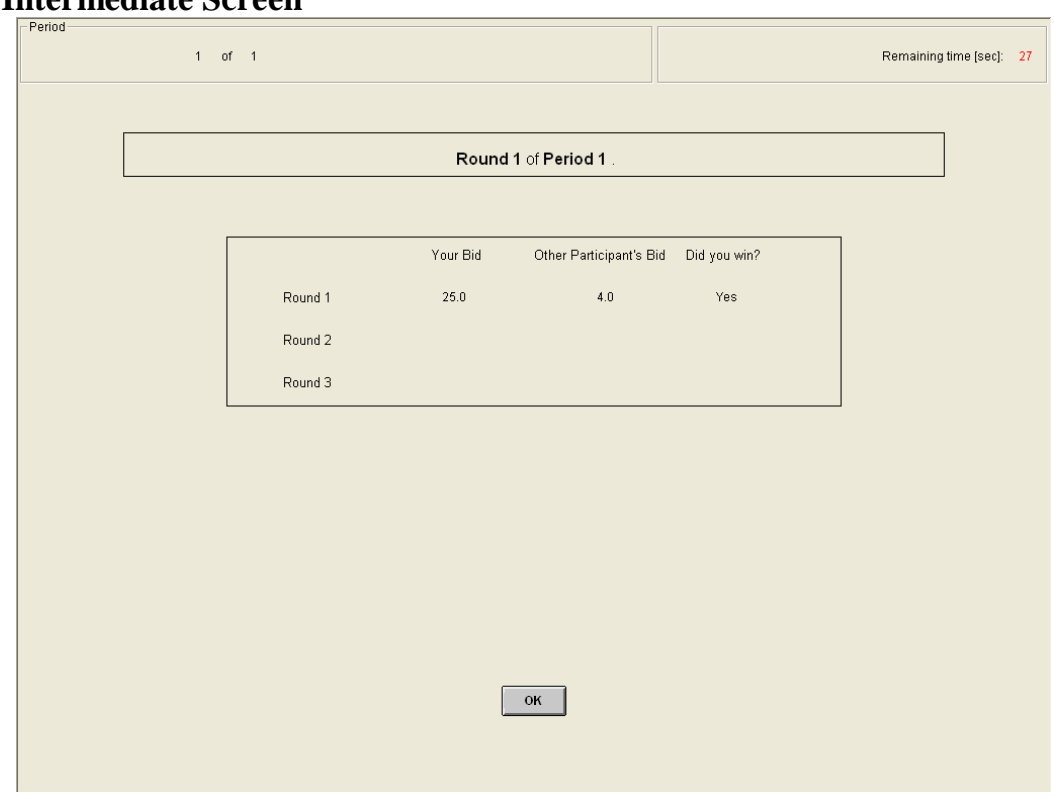

\section{END OF THE PERIOD}

The period ends when one of the participants in the group wins two rounds. At the end of the period, the computer will calculate your period earnings based on the number of rounds you won and how many francs you spent on bidding in each round. Your earnings from that period will be reported on the outcome screen as shown in Figure 3. Once the outcome screen is displayed you should record your results for the period on your Personal 
Record Sheet under the appropriate heading. You will be randomly re-matched with a different participant at the start of the next period.

Figure 3 - Outcome Screen

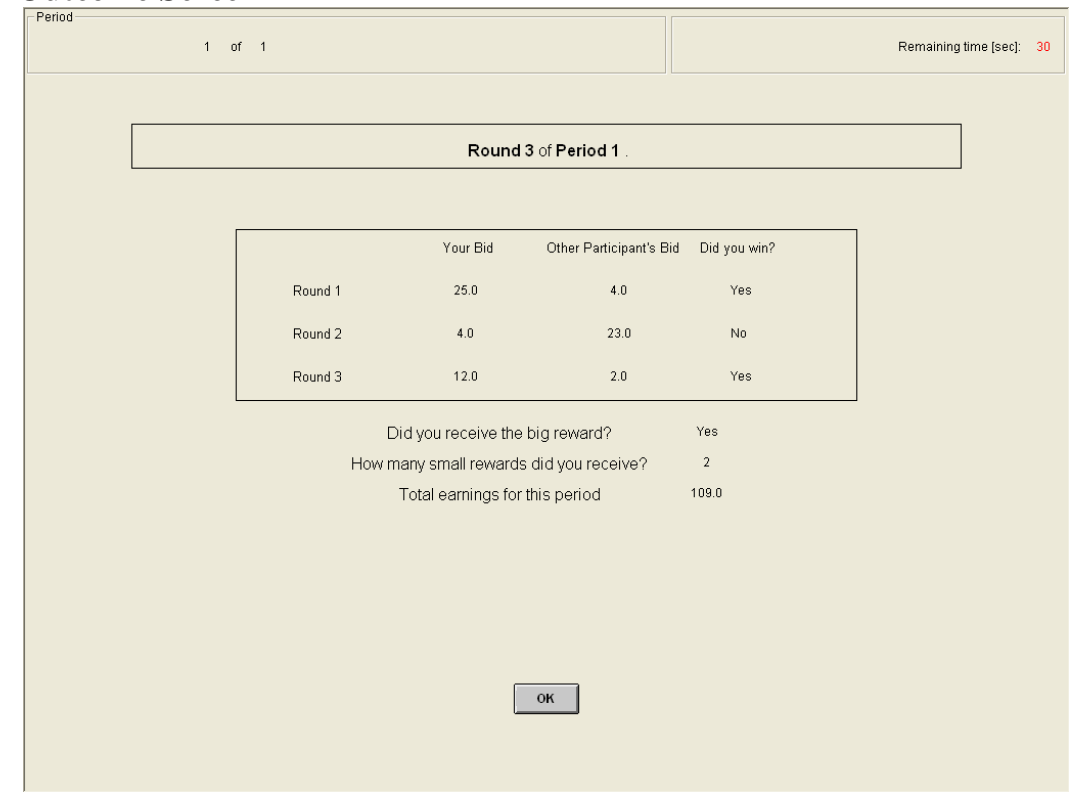

\section{END OF THE EXPERIMENT}

At the end of the experiment we will use the bingo cage to randomly select 2 out of 20 periods for actual payment. Depending on the outcome in a given period, you may receive either positive or negative earnings. You will sum the total earnings for these 2 periods and convert them to a U.S. dollar payment, as shown on the last page of your personal record sheet. Remember you have already received a \$20.00 participation fee (equivalent to $\mathbf{5 0 0}$ francs). If your earnings from this part of the experiment are positive, we will add them to your participation fee. If your earnings are negative, we will subtract them from your participation fee.

Are there any questions?

Before we begin this part of the experiment, we request that you fill the following questionnaire. The only purpose of the questionnaire is to check your understanding of the instructions. The experiment will start as soon as everyone has completed the questionnaire and we have addressed any doubts or concerns. We will start with a few practice rounds with the Excel probability calculator. 
2012

\section{Economic Science Institute Working Papers}

12-29 Bigoni, M., Camera, G. and Casari, M. Strategies of Cooperation and Punishment among Students and Clerical Workers.

12-28 Camera, G. and Kim, J. Buyer's Equilibrium with Capacity Constraints and Restricted Mobility: A recursive approach.

12-27 Camera, G., Casari, M., and Bigoni, M. Binding Promises and Cooperation Among Strangers.

12-26 Schniter, E., Shields, T. and Dickhaut, J. Ageism \& Cooperation.

12-25 Gjerstad, S. and Smith, V. Balance Sheet Crises: Causes, Consequences and Responses.

12-24 Gómez-Miñambres, J., Corgnet, B. and Hernán-Gonzalez, R. Goal Setting and Monetary Incentives: When Large Stakes Are Not Enough.

12-23 Clots-Figueras, I., Hernán González, R., and Kujal, P. Asymmetry and Deception in the Investment Game.

12-22 Dechenaux, E., Kovenock, D. and Sheremeta, R. A Survey of Experimental Research on Contests, All-Pay Auctions and Tournaments.

12-21 Rubin, J. and Sheremeta, R. Principal-Agent Settings with Random Shocks.

12-20 Gómez-Miñambres, J. and Schniter, E. Menu-Dependent Emotions and Self-Control.

12-19 Schniter, E., Sheremeta, R., and Sznycer, D. Building and Rebuilding Trust with Promises and Apologies.

12-18 Shields, T. and Xin, B. Higher-order Beliefs in Simple Trading Models.

12-17 Pfeiffer, G. and Shields, T. Performance-Based Compensation and Firm Value: Experimental evidence.

12-16 Kimbrough, E. and Sheremeta, R. Why Can't We Be Friends? Entitlements, bargaining, and conflict.

12-15 Mago, S., Savikhin, A., and Sheremeta, R. Facing Your Opponents: Social identification and information feedback in contests.

12-14 McCarter, M., Kopelman, S., Turk, T. and Ybarra, C. Too Many Cooks Spoil the Broth: How the tragedy of the anticommons emerges in organizations. 
12-13 Chowdhury, S., Sheremeta, R. and Turocy, T. Overdissipation and Convergence in Rent-seeking Experiments: Cost structure and prize allocation rules.

12-12 Bodsky, R., Donato, D., James, K. and Porter, D. Experimental Evidence on the Properties of the California's Cap and Trade Price Containment Reserve.

12-11 Branas-Garza, P., Espin, A. and Exadaktylos, F. Students, Volunteers and Subjects: Experiments on social preferences.

12-10 Klose, B. and Kovenock, D. Extremism Drives Out Moderation.

12-09 Buchanan, J. and Wilson, B. An Experiment on Protecting Intellectual Property.

12-08 Buchanan, J., Gjerstad, S. and Porter, D. Information Effects in Multi-Unit Dutch Auctions.

12-07 Price, C. and Sheremeta, R. Endowment Origin, Demographic Effects and Individual Preferences in Contests.

12-06 Magoa, S. and Sheremeta, R. Multi-Battle Contests: An experimental study.

12-05 Sheremeta, R. and Shields, T. Do Liars Believe? Beliefs and Other-Regarding Preferences in Sender-Receiver Games.

12-04 Sheremeta, R., Masters, W. and Cason. T. Winner-Take-All and Proportional-Prize Contests: Theory and experimental results.

12-03 Buchanan, J., Gjerstad, S. and Smith, V. There's No Place Like Home.

12-02 Corgnet, B. and Rodriguez-Lara, I. Are you a Good Employee or Simply a Good Guy? Influence Costs and Contract Design.

12-01 Kimbrough, E. and Sheremeta, R. Side-Payments and the Costs of Conflict. 2011

11-20 Cason, T., Savikhin, A. and Sheremeta, R. Behavioral Spillovers in Coordination Games.

11-19 Munro, D. and Rassenti, S. Combinatorial Clock Auctions: Price direction and performance.

11-18 Schniter, E., Sheremeta, R., and Sznycer, D. Restoring Damaged Trust with Promises, Atonement and Apology.

11-17 Brañas-Garza, P., and Proestakis, A. Self-discrimination: A field experiment on obesity.

11-16 Brañas-Garza, P., Bucheli, M., Paz Espinosa, M., and García-Muñoz, T. Moral Cleansing and Moral Licenses: Experimental evidence.

11-15 Caginalp, G., Porter, D., and Hao, L. Asset Market Reactions to News: An experimental study. 
11-14 Benito, J., Branas-Garz, P., Penelope Hernandez, P., and Sanchis Llopis, J. Strategic Behavior in Schelling Dynamics: A new result and experimental evidence.

11-13 Chui, M., Porter, D., Rassenti, S. and Smith, V. The Effect of Bidding Information in Ascending Auctions.

11-12 Schniter, E., Sheremeta, R. and Shields, T. Conflicted Minds: Recalibrational emotions following trust-based interaction.

11-11 Pedro Rey-Biel, P., Sheremeta, R. and Uler, N. (Bad) Luck or (Lack of) Effort?: Comparing social sharing norms between US and Europe.

11-10 Deck, C., Porter, D., and Smith, V. Double Bubbles in Assets Markets with Multiple Generations.

11-09 Kimbrough, E., Sheremeta, R., and Shields, T. Resolving Conflicts by a Random Device.

11-08 Brañas-Garza, P., García-Muñoz, T., and Hernan, R. Cognitive effort in the Beauty Contest Game.

11-07 Grether, D., Porter, D., and Shum, M. Intimidation or Impatience? Jump Bidding in On-line Ascending Automobile Auctions.

11-06 Rietz, T., Schniter, E., Sheremeta, R., and Shields, T. Trust, Reciprocity and Rules.

11-05 Corgnet, B., Hernan-Gonzalez, R., and Rassenti, S. Real Effort, Real Leisure and Real-time Supervision: Incentives and peer pressure in virtual organizations.

11-04 Corgnet, B. and Hernán-González R. Don’t Ask Me If You Will Not Listen: The dilemma of participative decision making.

11-03 Rietz, T., Sheremeta, R., Shields, T., and Smith, V. Transparency, Efficiency and the Distribution of Economic Welfare in Pass-Through Investment Trust Games.

11-02 Corgnet, B., Kujal, P. and Porter, D. The Effect of Reliability, Content and Timing of Public Announcements on Asset Trading Behavior.

11-01 Corgnet, B., Kujal, P. and Porter, D. Reaction to Public Information in Markets: How much does ambiguity matter?

\section{0}

10-23 Sheremeta, R. Perfect-Substitutes, Best-Shot, and Weakest-Link Contests between Groups.

10-22 Mago, S., Sheremeta, R., and Yates, A. Best-of-Three Contests: Experimental evidence.

10-21 Kimbrough, E. and Sheremeta, R. Make Him an Offer He Can't Refuse: Avoiding conflicts through side payments. 
10-20 Savikhim, A. and Sheremeta, R. Visibility of Contributions and Cost of Inflation: An experiment on public goods.

10-19 Sheremeta, R. and Shields, T. Do Investors Trust or Simply Gamble?

10-18 Deck, C. and Sheremeta, R. Fight or Flight? Defending Against Sequential Attacks in the Game of Siege.

10-17 Deck, C., Lin, S. and Porter, D. Affecting Policy by Manipulating Prediction Markets: Experimental evidence.

10-16 Deck, C. and Kimbrough, E. Can Markets Save Lives? An Experimental Investigation of a Market for Organ Donations.

10-15 Deck, C., Lee, J. and Reyes, J. Personality and the Consistency of Risk Taking Behavior: Experimental evidence.

10-14 Deck, C. and Nikiforakis, N. Perfect and Imperfect Real-Time Monitoring in a Minimum-Effort Game.

10-13 Deck, C. and Gu, J. Price Increasing Competition? Experimental Evidence.

10-12 Kovenock, D., Roberson, B., and Sheremeta, R. The Attack and Defense of Weakest-Link Networks.

10-11 Wilson, B., Jaworski, T., Schurter, K. and Smyth, A. An Experimental Economic History of Whalers' Rules of Capture.

10-10 DeScioli, P. and Wilson, B. Mine and Thine: The territorial foundations of human property.

10-09 Cason, T., Masters, W. and Sheremeta, R. Entry into Winner-Take-All and Proportional-Prize Contests: An experimental study.

10-08 Savikhin, A. and Sheremeta, R. Simultaneous Decision-Making in Competitive and Cooperative Environments.

10-07 Chowdhury, S. and Sheremeta, R. A generalized Tullock contest.

10-06 Chowdhury, S. and Sheremeta, R. The Equivalence of Contests.

10-05 Shields, T. Do Analysts Tell the Truth? Do Shareholders Listen? An Experimental Study of Analysts' Forecasts and Shareholder Reaction.

10-04 Lin, S. and Rassenti, S. Are Under- and Over-reaction the Same Matter? A Price Inertia based Account.

10-03 Lin, S. Gradual Information Diffusion and Asset Price Momentum.

10-02 Gjerstad, S. and Smith, V. Household Expenditure Cycles and Economic Cycles, 1920 - 2010. 
10-01 Dickhaut, J., Lin, S., Porter, D. and Smith, V. Durability, Re-trading and Market Performance.

\section{9}

09-11 Hazlett, T., Porter, D., and Smith, V. Radio Spectrum and the Disruptive Clarity OF Ronald Coase.

09-10 Sheremeta, R. Expenditures and Information Disclosure in Two-Stage Political Contests.

09-09 Sheremeta, R. and Zhang, J. Can Groups Solve the Problem of Over-Bidding in Contests?

09-08 Sheremeta, R. and Zhang, J. Multi-Level Trust Game with "Insider" Communication.

09-07 Price, C. and Sheremeta, R. Endowment Effects in Contests.

09-06 Cason, T., Savikhin, A. and Sheremeta, R. Cooperation Spillovers in Coordination Games.

09-05 Sheremeta, R. Contest Design: An experimental investigation.

09-04 Sheremeta, R. Experimental Comparison of Multi-Stage and One-Stage Contests.

09-03 Smith, A., Skarbek, D., and Wilson, B. Anarchy, Groups, and Conflict: An experiment on the emergence of protective associations.

09-02 Jaworski, T. and Wilson, B. Go West Young Man: Self-selection and endogenous property rights.

09-01 Gjerstad, S. Housing Market Price Tier Movements in an Expansion and Collapse.

\section{8}

08-09 Dickhaut, J., Houser, D., Aimone, J., Tila, D. and Johnson, C. High Stakes Behavior with Low Payoffs: Inducing preferences with Holt-Laury gambles.

08-08 Stecher, J., Shields, T. and Dickhaut, J. Generating Ambiguity in the Laboratory.

08-07 Stecher, J., Lunawat, R., Pronin, K. and Dickhaut, J. Decision Making and Trade without Probabilities.

08-06 Dickhaut, J., Lungu, O., Smith, V., Xin, B. and Rustichini, A. A Neuronal Mechanism of Choice.

08-05 Anctil, R., Dickhaut, J., Johnson, K., and Kanodia, C. Does Information Transparency Decrease Coordination Failure?

08-04 Tila, D. and Porter, D. Group Prediction in Information Markets With and Without Trading Information and Price Manipulation Incentives.

08-03 Thomas, C. and Wilson, B. Horizontal Product Differentiation in Auctions and Multilateral Negotiations. 
08-02 Oprea, R., Wilson, B. and Zillante, A. War of Attrition: Evidence from a laboratory experiment on market exit.

08-01 Oprea, R., Porter, D., Hibbert, C., Hanson, R. and Tila, D. Can Manipulators Mislead Prediction Market Observers? 